\title{
Nanodiamond Promotes Surfactant-Mediated Triglyceride Removal from a \\ Hydrophobic Surface at or below Room Temperature
}

\section{Supporting Information}

Xianjin Cui, ${ }^{\mathrm{b}}$ Xianping Liu, ${ }^{\mathrm{c}}$ Andrew S. Tatton, ${ }^{\mathrm{d}}$ Steven P. Brown, ${ }^{\mathrm{d}}$ Haitao Ye, ${ }^{\mathrm{a}}$ and Andrew Marsh. $^{b^{*}}$

[a] School of Engineering and Applied Science, Aston University, Birmingham, B4 7ET

Email: h.ye@aston.ac.uk

[b] Department of Chemistry, University of Warwick, Coventry, CV4 7AL

Email: a.marsh@warwick.ac.uk

[c] School of Engineering, University of Warwick, Coventry, CV4 7AL

Email: x.liu@warwick.ac.uk

[d] Department of Physics, University of Warwick, Coventry CV4 7AL

Email: s.p.brown@warwick.ac.uk

\section{General Experimental}

Tristearin lipid and $N, N$-dimethyldodecylamine $N$-oxide were purchased from Tokyo Chemical Industry (TCI) Ltd. Diamond nanopowder 97\% (ND97) and other chemicals were purchased from Sigma-Aldrich. All chemicals are used as purchased without purification. Zeta potential and average size of particles in solution were measured by dynamic light scattering (DLS) on a Malvern Zetasizer using a $633 \mathrm{~nm}$ laser with a measuring angle of $173^{\circ}$. QCM-D data were recorded on a Q-Sense E4 from $Q$-Sense $A B$, Sweden at $15^{\circ} \mathrm{C}$ and $25^{\circ} \mathrm{C}$ and processed using QTools software. Powder X-ray Diffraction (PXRD) was carried out on a Bruker D5000 powder X-ray diffractometer with $\mathrm{Cu} \mathrm{K}$-alpha radiation. Transmission electronic microscope (TEM) images were obtained on JEOL2100 in the Department of Physics, University of Warwick. Raman spectra were recorded on a Renishaw inVia Raman Microscope with a CCD detector and a laser of $514.5 \mathrm{~nm}$. Infrared (IR) Spectra were recorded on a PerkinElmer Spectrum 100 FT-IR spectrometer, using attenuated total reflectance. 
S1. Characterization of diamond nanoparticles by TEM, X-ray powder diffraction and infra-red spectroscopy.

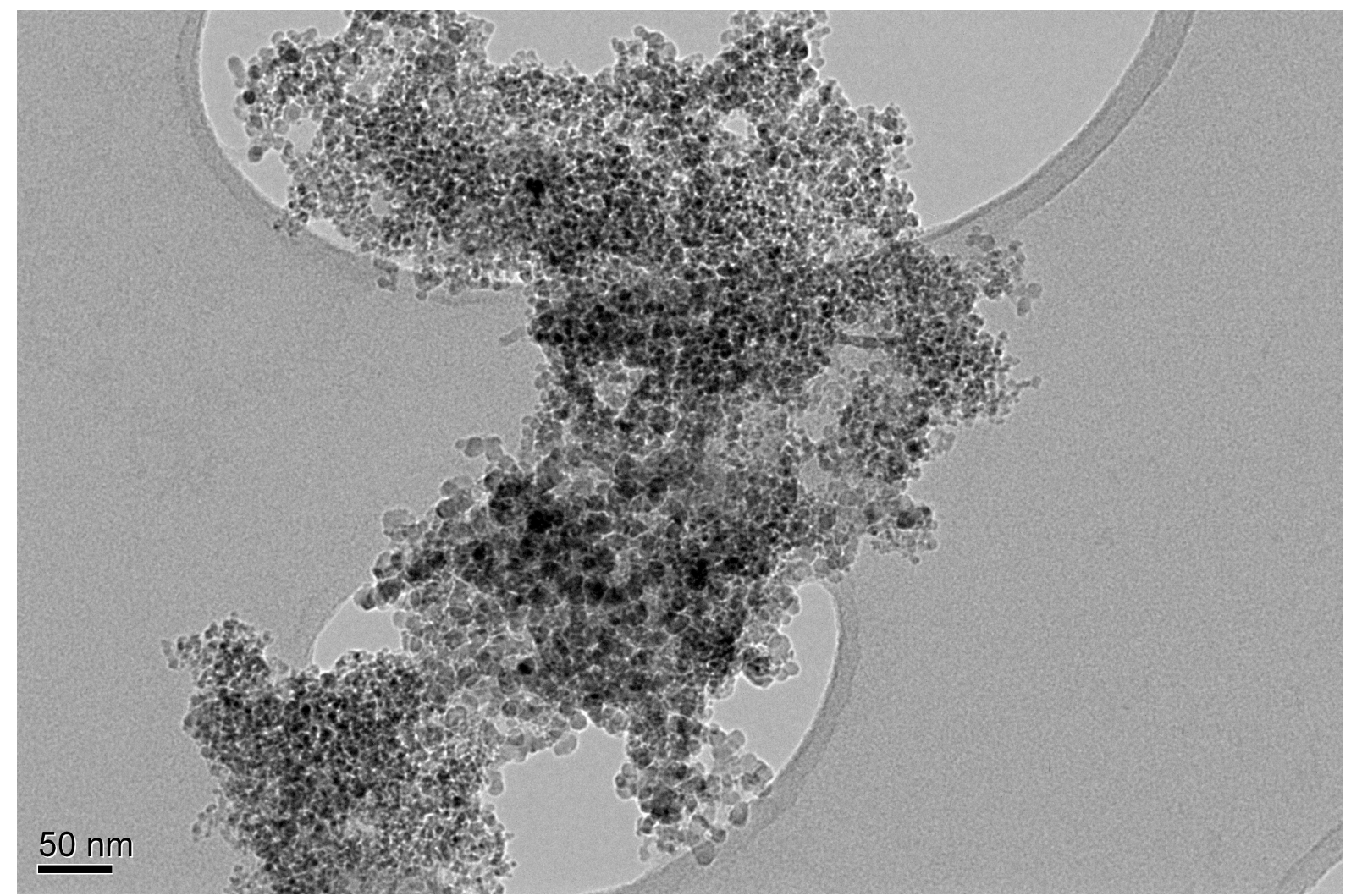

Figure S1. Raw nanodiamond ND97 showing large aggregates of $c a .5 \mathrm{~nm}$ particles. 


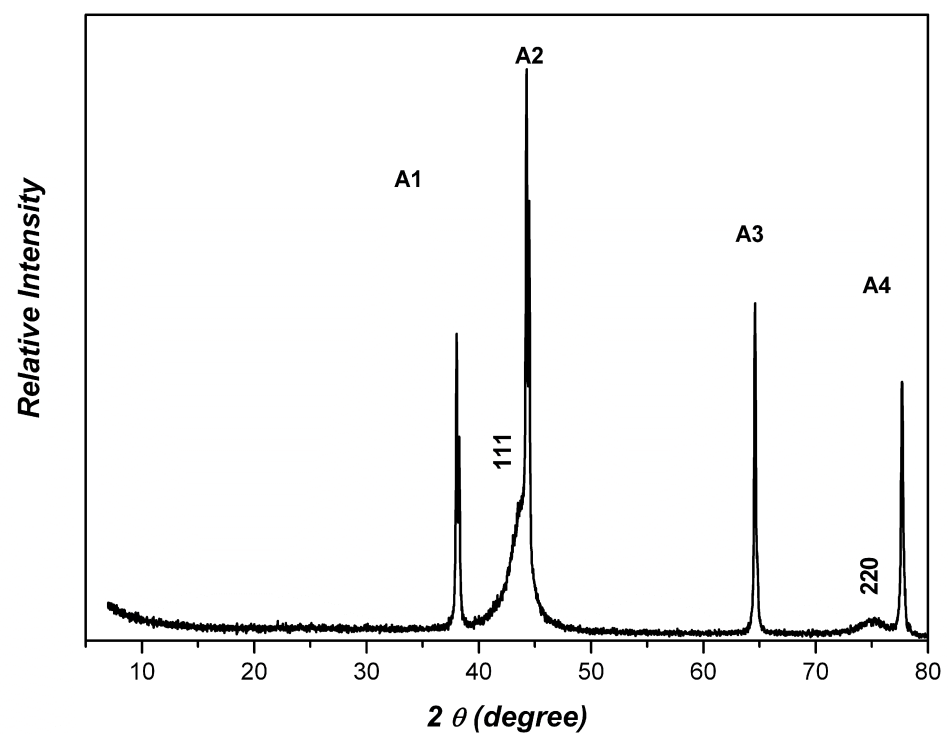

Figure S2: Pattern of X-ray powder diffraction of diamond nanoparticles (ND97). Strong and sharp peaks labelled A1-A4 belong to the aluminium holder. Weak peaks at $44^{\circ}$ and $75^{\circ}$ were indexed as the diffraction peaks of (111), (220) planes of cubic diamond respectively.
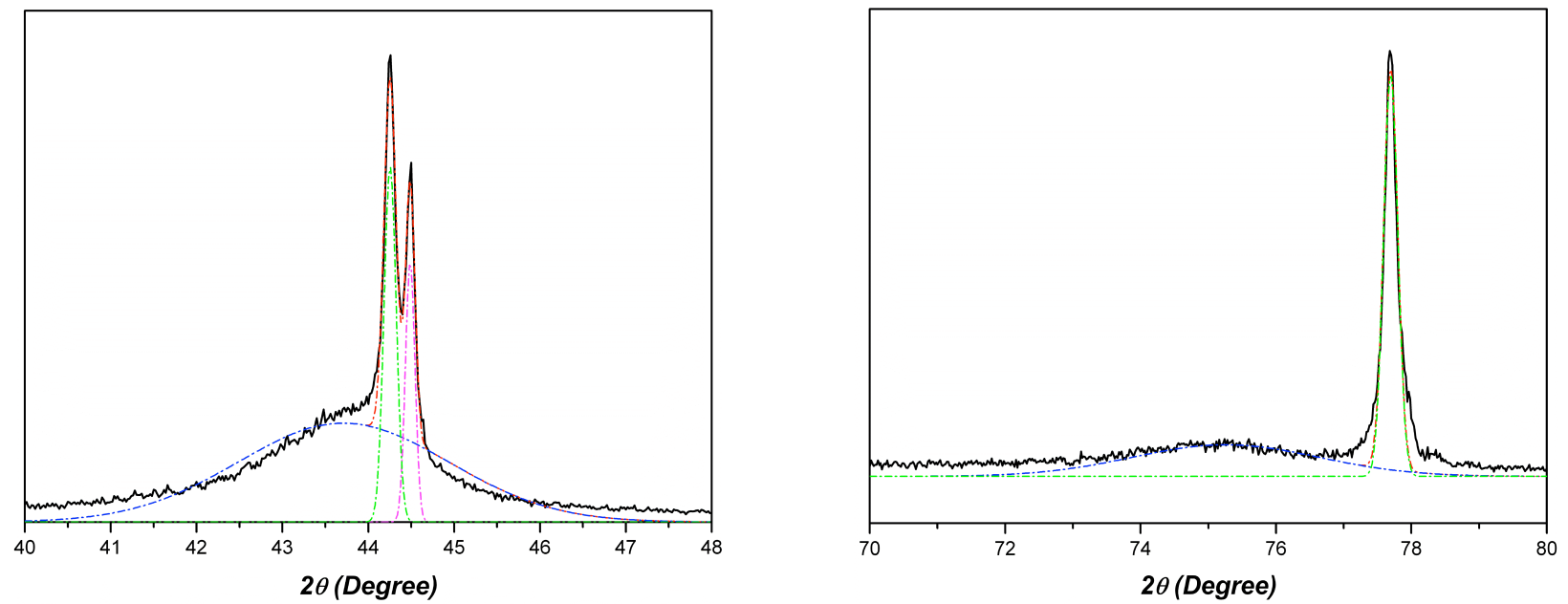

Figure S2A. Gaussian fitting of peaks at around $44^{\circ}$ and $75^{\circ}$. 


\begin{tabular}{|c|c|c|c|c|c|c|}
\hline Peak + assignment & $\begin{array}{c}A l \\
\text { A1 }\end{array}$ & $\begin{array}{c}A l \\
\text { A2 }\end{array}$ & $\begin{array}{c}A l \\
\text { A3 }\end{array}$ & $\begin{array}{c}A l \\
\text { A4 }\end{array}$ & $\begin{array}{c}\text { ND97 } \\
(111)\end{array}$ & $\begin{array}{c}\text { ND97 } \\
(220)\end{array}$ \\
\hline Position $\left(2 \theta,^{\circ}\right)$ & 38.03 & 44.4 & 64.6 & 77.67 & 43.7 & 75.2 \\
\hline FWHM $\left(\mathrm{b}_{0},{ }^{\circ}\right)$ & 0.14 & 0.14 & 0.15 & 0.2 & 2.4 & 2.7 \\
\hline FWHM (b ${ }_{0}$, radians) & $2.44^{-3} 10^{-3}$ & $2.44 * 10^{-3}$ & $2.62 * 10^{-3}$ & $3.49 * 10^{-3}$ & $4.19^{*} 10^{-2}$ & $4.71 * 10^{-2}$ \\
\hline
\end{tabular}

Table S1. The position and full width at half maximum (FWHM) of peaks. $A l=$ peaks assigned to the aluminium sample holder, $N D 97=$ peaks assigned to diamond nanoparticles. The position and FWHM was measured manually or given by Gaussian fitting using Origin ${ }^{\circledR}$ (Figure S1A).

The mean size (diameter) $\tau$ of nanoparticles can be estimated from X-ray diffraction using the Scherrer equation (Equation S4).

$$
\tau=\frac{K \lambda}{\beta \cos \theta}=\frac{K \lambda}{\left(b-b_{0}\right) \cos \theta}
$$

\section{Equation S1}

Where $K$ represents the shape factor, typically taken to be $0.9, \beta$ represents the line broadening at half the maximum intensity (radians), $\theta$ represents the Bragg angle, $\lambda$ the X-ray wavelength $(\AA), b$ and $b_{0}$ represent the FWHM for the nanoparticles and the standard crystal respectively. The wavelength of $\mathrm{K} \alpha_{1} \mathrm{X}$-ray radiation used is $1.5406 \AA$. The value of $b_{0}$ at $43.7^{\circ}$ and $75.2^{\circ}$ was calculated as $0.14^{\circ}$ and $0.2^{\circ}$ respectively, using the highly crystalline aluminium holder as the standard. Hence, the mean size of diamond nanoparticles was calculated to be $c a .4 \mathrm{~nm}$ as follows:

$$
\begin{aligned}
& \tau_{(111)}=\frac{0.9 \lambda}{\left(b-b_{0}\right) \cos \theta}=\frac{0.9 \times 1.5406 \AA}{\left(4.19 \times 10^{-2}-2.44 \times 10^{-3}\right) \cos 21.85^{\circ}}=37.8 \AA \\
& \tau_{(220)}=\frac{0.9 \lambda}{\left(b-b_{0}\right) \cos \theta}=\frac{0.9 \times 1.5406 \AA}{\left(4.71 \times 10^{-2}-2.62 \times 10^{-3}\right) \cos 21.85^{\circ}}=33.6 \AA
\end{aligned}
$$

Nanoparticles could be larger than predicted by the Scherrer equation because crystal size is not the only factor responsible for broadening of the diffraction peaks and this is usually viewed as an estimate only. 


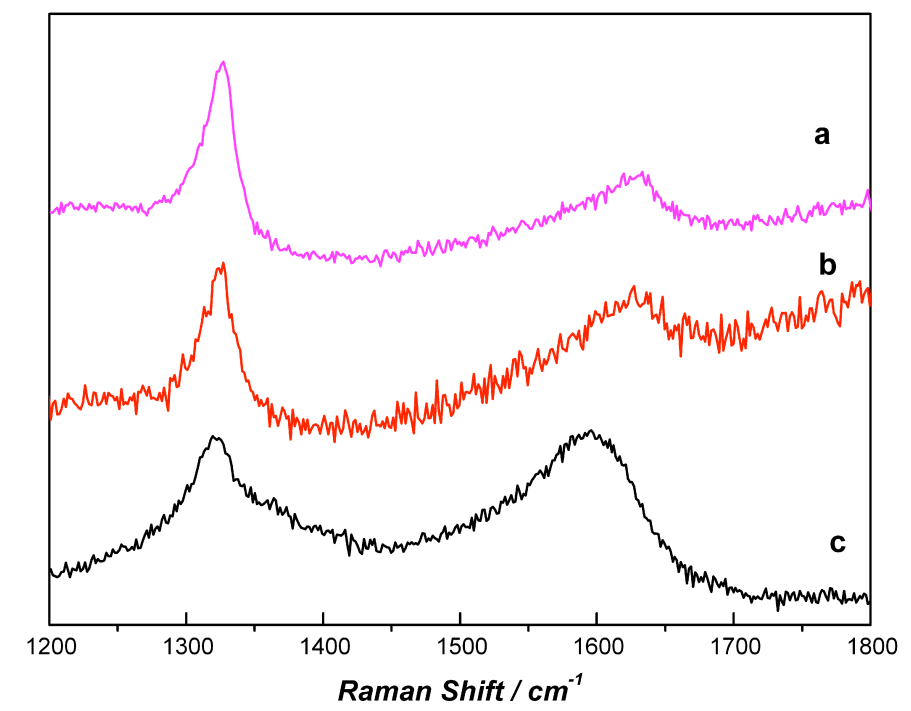

Figure S3. Raman spectra of nanodiamond samples: (a) products obtained by heating ND97 in air at $485{ }^{\circ} \mathrm{C}$ for 5 hours; (b) products obtained by heating ND97 in the air at $485{ }^{\circ} \mathrm{C}$ for 3 hours; and (c) reference spectrum of untreated ND97. The peaks at $1330 \mathrm{~cm}^{-1}$ and $1600 \mathrm{~cm}^{-1}$ can be attributed to ' $\mathrm{sp}^{3}$ ' and ' $\mathrm{sp}^{2}$ ' carbon respectively. Excitation wavelength is $514.5 \mathrm{~nm}$.

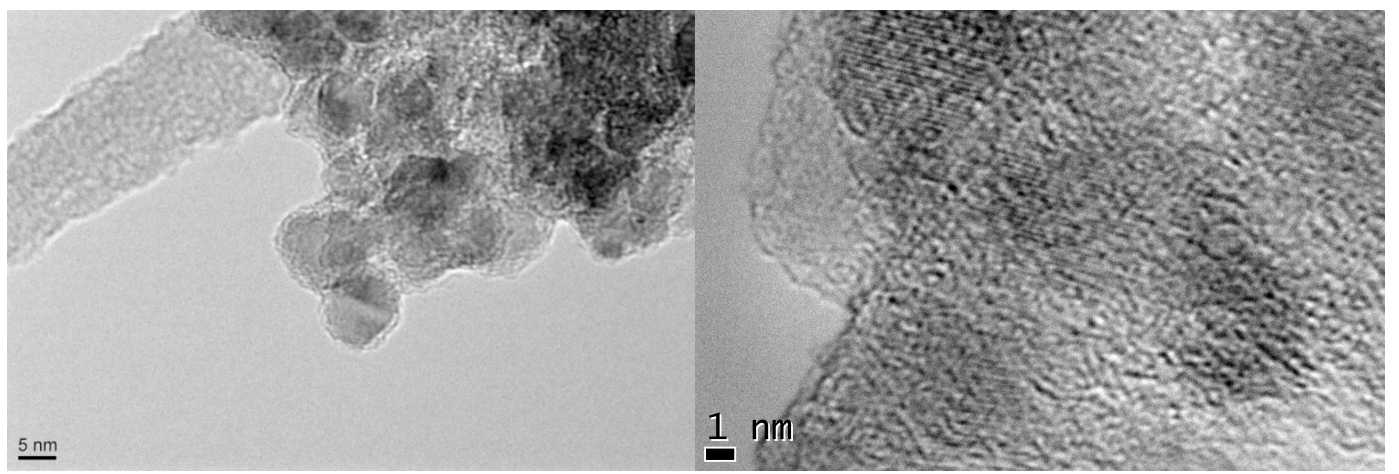

Figure S4. TEM images of diamond nanoparticles before (ND97, left) and after (1, right) thermal oxidation showing removal of paler surface associated amorphous carbon and revealing $\mathrm{sp}^{3}$ diamond-like lattice. 


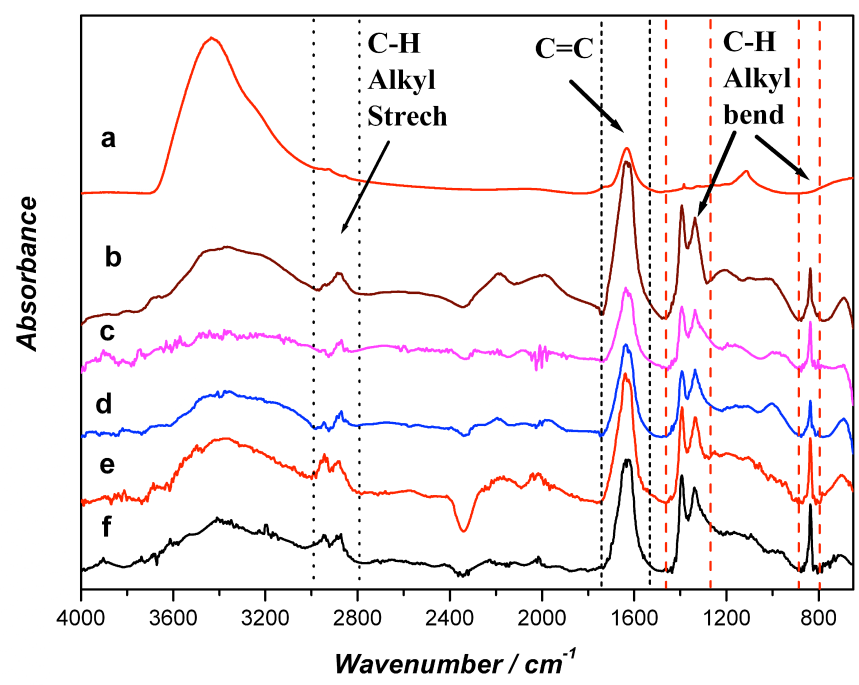

Figure S5. IR spectra of nanodiamond powder exposed to $\mathrm{H}_{2}$ plasma for 10 minutes at different powers of microwave generator: a) reference spectrum of ND97; b) $1200 \mathrm{~W}$; c) $1100 \mathrm{~W}$; d) $1000 \mathrm{~W}$; e) $900 \mathrm{~W}$; and f) $800 \mathrm{~W}$. 


\section{S2. Structures of surfactants used}

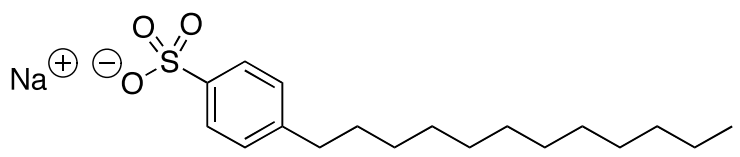

sodium dodecylbenzenesulfonate (SDBS)

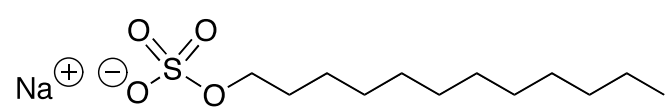

sodium dodecylsulfate (SDS)<smiles>CCCCCCCCCCCCCCCC[N+](C)(C)C</smiles>

hexadecyltrimethylammonium bromide (cetyl trimethylammonium bromide, CTAB)<smiles>CCCCCCCCCCCC[N+](C)(C)[O-]</smiles>

$\mathrm{N}, \mathrm{N}$-dimethyldodecylamine $\mathrm{N}$-oxide (DDAO) or lauryl $\mathrm{N}, \mathrm{N}$-dimethylamine $\mathrm{N}$-oxide (LDAO)

$\mathrm{H}^{\mathrm{O}} \mathrm{\gamma OH}_{\mathrm{m}}$

polyethylene glycol, $M_{n}=1000(P E G-1000)$

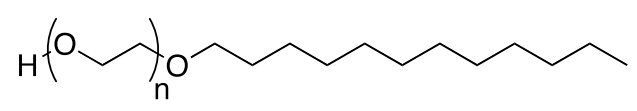

polyethylene glycol dodecyl ethyl $\left(\mathrm{Brij}^{\circledR} 35\right)$

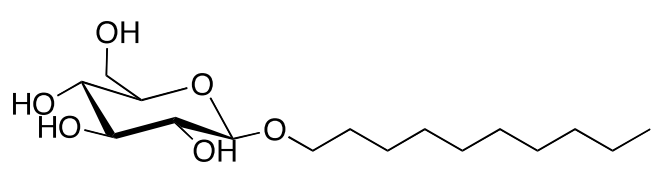

decyl $\beta$-D-glucopyranoside $\left(\mathrm{G}_{1} \mathrm{C}_{10}\right)$

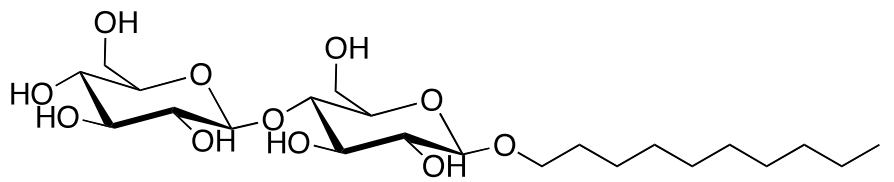

decyl $\beta$-D-maltopyranoside $\left(G_{2} C_{10}\right)$

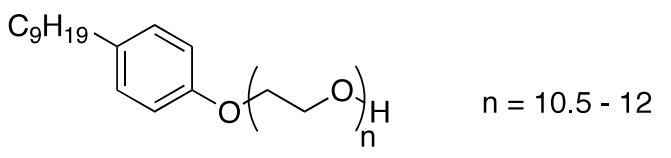

polyoxyethylene(12) nonylphenylether, branched $\left(\mathrm{NFE}_{10}\right)$<smiles>CCCCCCCCCCCCCCCC(=O)OCC(COC(=O)CCCCCCCCCCCCCCC)OC(=O)CCCCCCCCCCCCCCC</smiles>

lipid: tristearin

Figure S6. Structures of surfactants and lipid used. 
S3. Nanodiamond and colloid characterisation

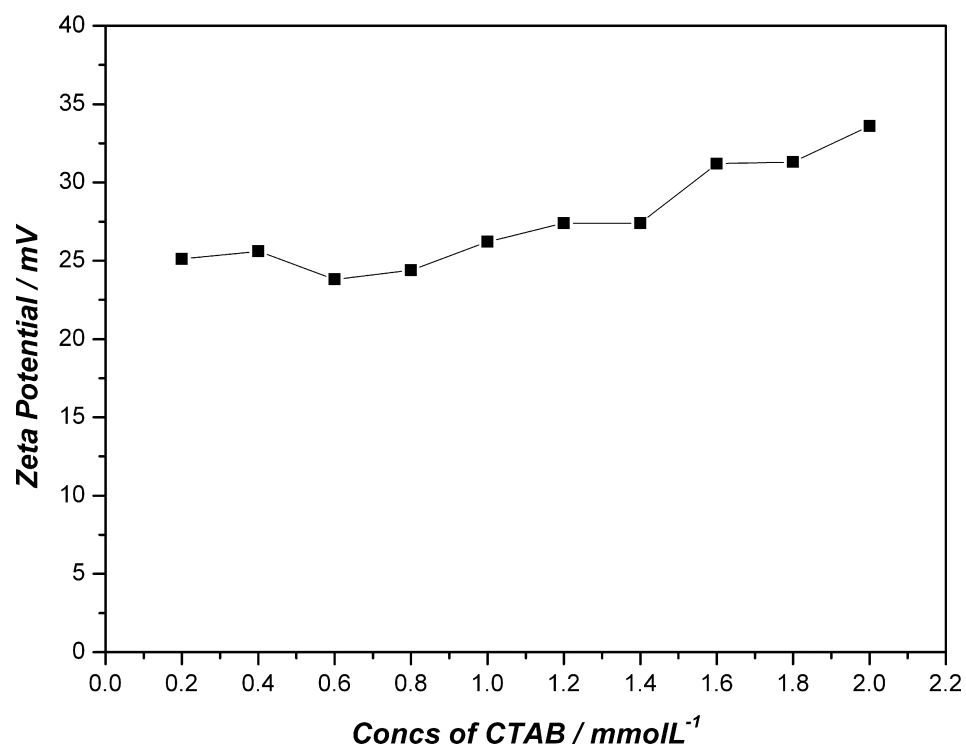

Figure S7. Correlation between the zeta potential of diamond ND97 nanoparticles and concentration of the surfactant CTAB. [ND97] $=0.1 \mathrm{~g} / \mathrm{L}, \mathrm{T}=25^{\circ} \mathrm{C}$.

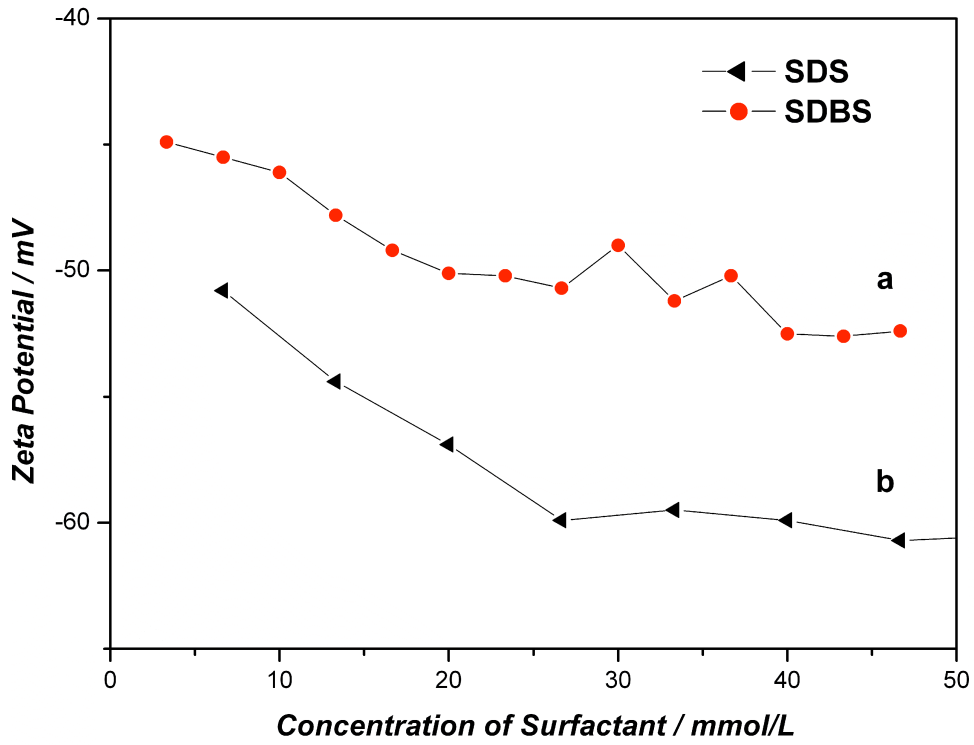

Figure S8. Correlation between the zeta potential of diamond ND97 nanoparticles and concentration of surfactant: (a) SDS, and (b) SDBS. [ND97] $=0.1 \mathrm{~g} / \mathrm{L}, \mathrm{T}=25^{\circ} \mathrm{C}$. 


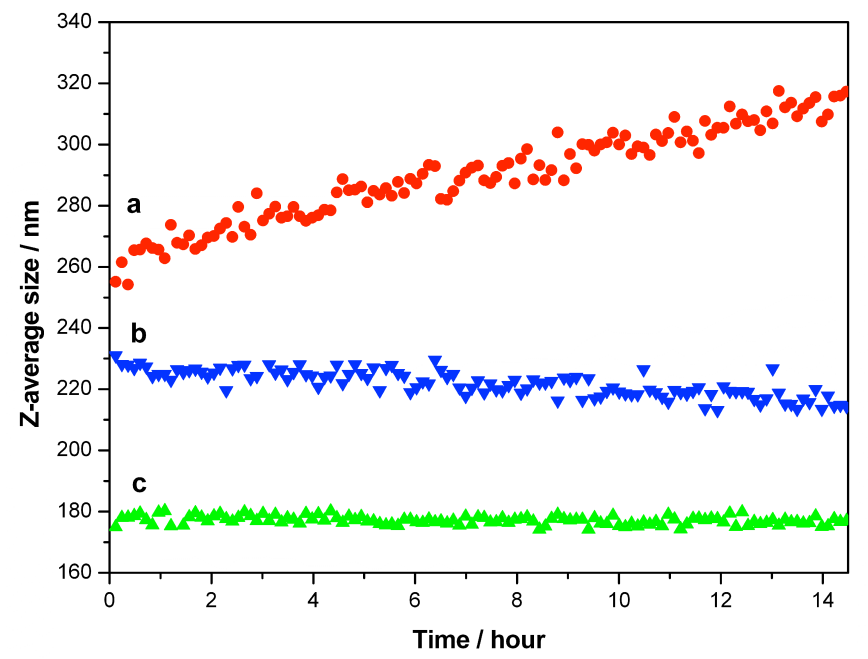

Figure S9. Average size of nanoparticle aggregates in solution over time measured by DLS: (a) ND97 in $40 \mathrm{mmol} / \mathrm{L}$ SDBS aqueous solution, (b) ND97 in $10 \mathrm{mmol} / \mathrm{L}$ SDBS aqueous solution, and (c) ND97 in $2 \mathrm{mmol} / \mathrm{L} \mathrm{CTAB}$ aqueous solution. [ND97] $=0.1 \mathrm{~g} / \mathrm{L}, \mathrm{T}=25^{\circ} \mathrm{C}$.

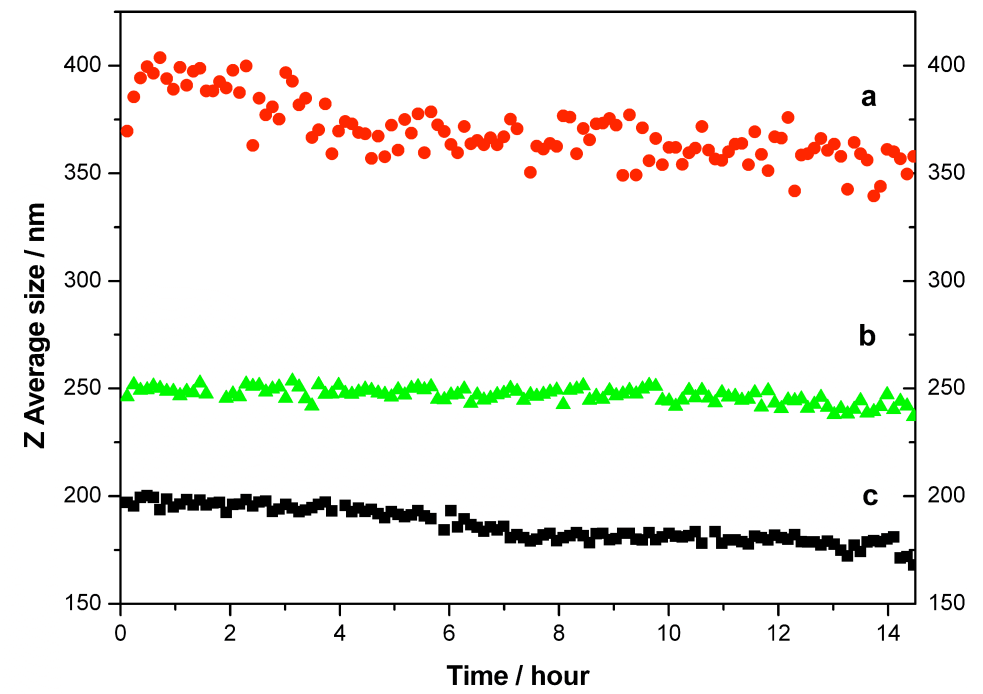

Figure S10. Curves of the average size against time of ND97 in solutions of non-ionic surfactants: (a) Brij ${ }^{\circledR} 35$, (b) PEG-1000, (c) DDAO. [ND97] $=0.1 \mathrm{~g} / \mathrm{L},\left[\right.$ Brij $\left.^{\circledR} 35\right]=[\mathrm{PEG}-$ $1000]=8 \mathrm{~g} / \mathrm{L},[\mathrm{DDAO}]=40 \mathrm{mmol} / \mathrm{L} ; \mathrm{T}=25^{\circ} \mathrm{C}$. 


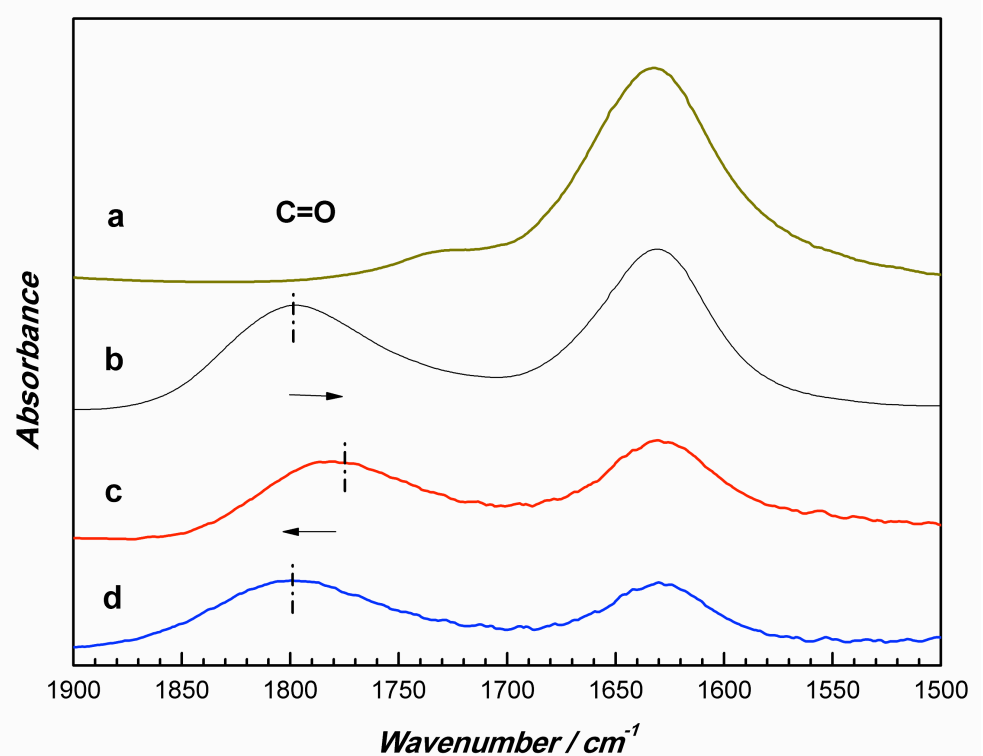

Figure S11. IR spectra of nanodiamond samples: (a) untreated ND97; (b) after heating in air at $485{ }^{\circ} \mathrm{C}$ for 3 hours; and (c) after a base treatment with $\mathrm{KOH}$ solution, and (d) after an acid treatment with $\mathrm{HCl}$ solution. Oxidized ND97 obtained by a thermal treatment was immersed in a $3 \mathrm{M} \mathrm{KOH}$ aqueous solution, and then moved into a $3 \mathrm{M} \mathrm{HCl}$ aqueous solution.

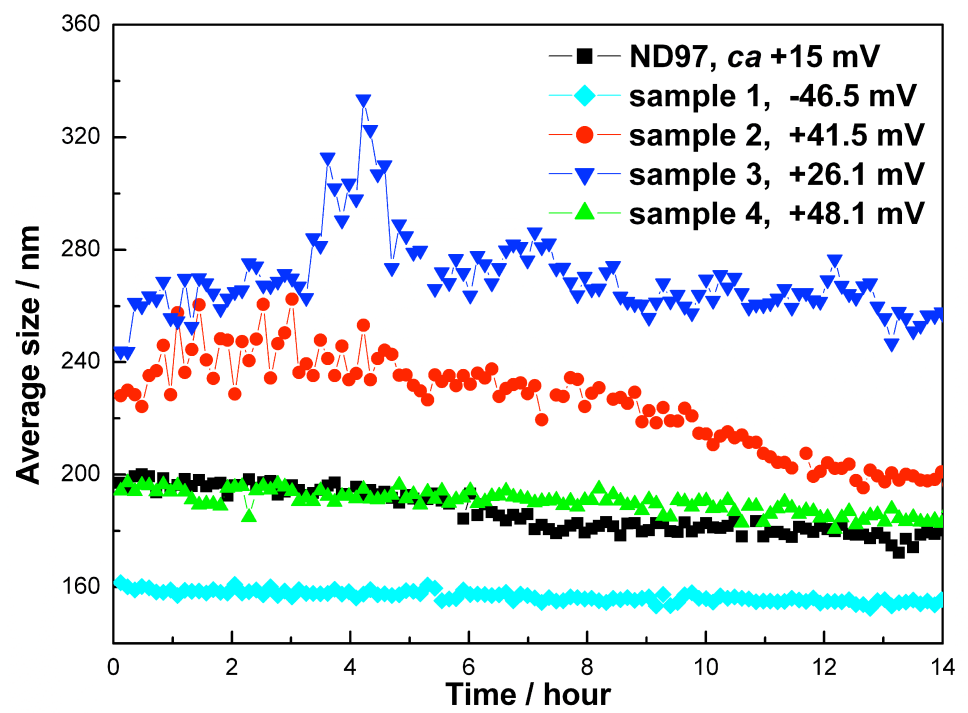

Figure S12. Curves of Z-average size of functionalised diamond nanoparticles in water over time. $[\mathrm{ND97}]=[\mathbf{1}]=[\mathbf{2}]=[3]=[4]=0.1 \mathrm{~g} / \mathrm{L}$. 


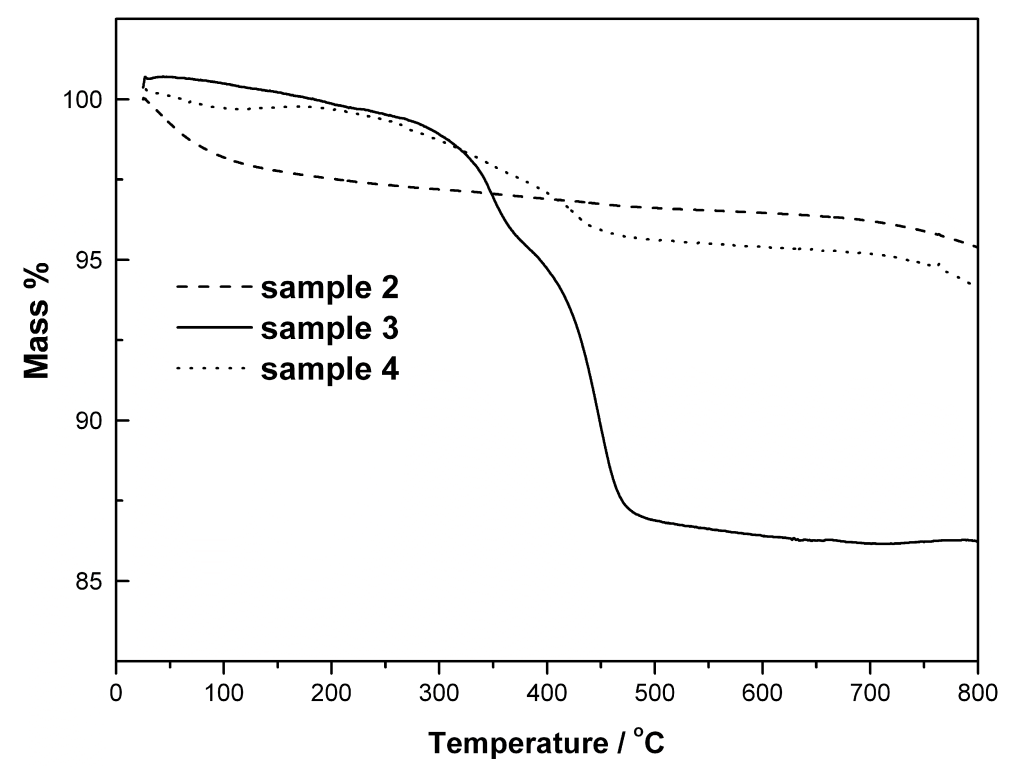

Figure S13. Thermogravimetric curves of starting materials 2, alkylamine functionalised diamond nanoparticles 4; and alkylcarboxyl functionalised diamond nanoparticles $\mathbf{3}$.

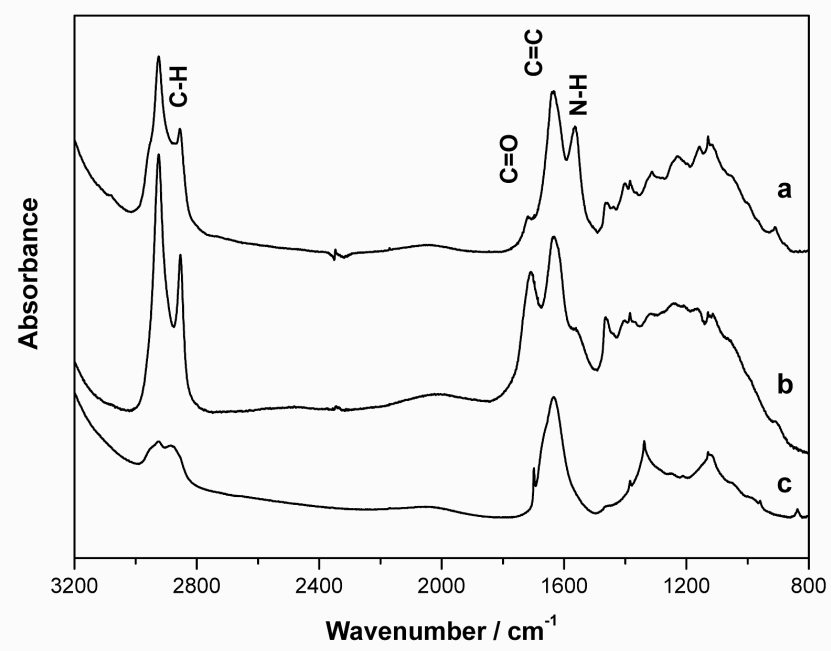

Figure S14. IR spectra of functionalised diamond nanoparticles: a) $\omega$-alkyl- $N$ methylpiperazine amide functionalised diamond nanoparticles 4; b) $\omega$-alkylcarboxyl functionalised diamond nanoparticles 3 , and c) reference spectrum of starting material 2. 


\section{S4. Methods for Quartz Crystal Microbalance preparation and measurements}

Quartz crystal microbalance (QCM) and the proprietary monitoring of signal dissipation (QCM-D) are based on the oscillation of a thin piezoelectric quartz crystal induced by an oscillating electric field. The change in mass of the crystal induces a proportional change in the frequency of the oscillation. If the adsorbed film is thin, rigid and evenly distributed, the additional mass can be calculated from the changes in frequency by the Sauerbrey equation (Equation S4):

$$
\begin{array}{ll}
\Delta m=-k \times \frac{\Delta f}{n} \quad \text { Equation } \mathrm{S} 4
\end{array}
$$

Where $\Delta m$ is the adsorbed mass, $\Delta f$ represents the change in frequency, $k$ is a crystaldependent constant, and $n$ is the overtone number. The oscillation frequency of a crystal in contact with a liquid, as is the case here, may not obey the Sauerbrey equation. ${ }^{1,2}$ In addition to the frequency, QCM-D can also simultaneously measure the dissipation, ${ }^{1,3}$ allowing us to analyse the viscoelastic properties of the film, which is useful for interpretation of measurements of our non-rigid lipid films. ${ }^{3-5}$ However, interpretation is sensitive to the modelling parameters, and hence all data presented herein are without modification. Frequency and dissipation signals were monitored for six overtone frequencies (1st, 3rd, 5th, 7th, 9th and 11th) but data are presented only for the 3rd overtone as the other signals exhibited similar behaviour.

QCM-D experimental: To remove air in the reaction chamber inside the cell, pure water was pumped into the cell until no bubbles could be observed in the tubes. In the first few minutes, water was used to obtain a stable baseline, and then swapped to buffers (surfactant solutions or nanodiamond colloids) for lipid removal. After reaching equilibrium, buffers were switched to surfactant solution for 15 minutes and then to water for another 15 minutes for the purpose of cleaning. The rate of flow was maintained at $200 \mu \mathrm{L} / \mathrm{min}$ and all experiments were carried out at a cell temperature of $25^{\circ} \mathrm{C}$ or $15^{\circ} \mathrm{C}$. 
S5. QCM-D data for lipid removal by different surfactant with or without nanoparticles at $25^{\circ} \mathrm{C}$ (frequency and dissipation change to $3^{\text {rd }}$ overtone).

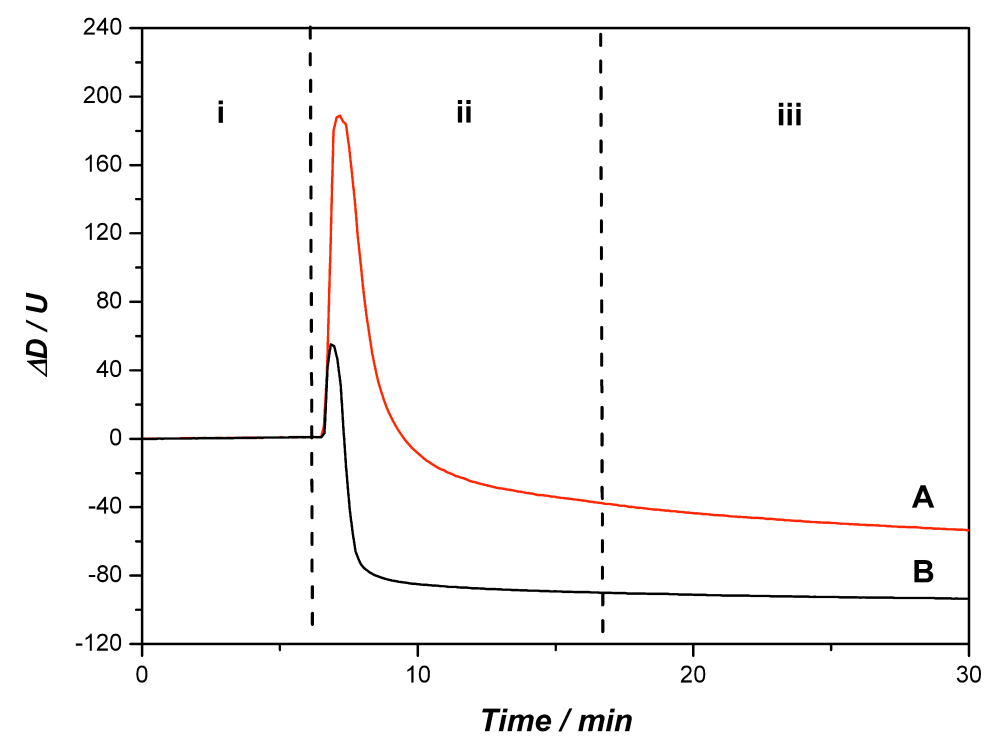

Figure S15. Dissipation changes to $3^{\text {rd }}$ overtone when the tristearin coated sensor was exposed to: i) 0-7 minutes, water is used for both sensors to obtain a stable baseline; ii) 7-17 minutes, SDBS/ND97 colloid and SDBS solution were used for sensor A and B respectively, to remove tristearin lipid; iii) 17-30 minutes SDBS solution was used for both sensors, to clean the QCM system. [SDBS] $=40 \mathrm{mmol} / \mathrm{L},[\mathrm{ND} 97]=0.1 \mathrm{~g} / \mathrm{L}$.

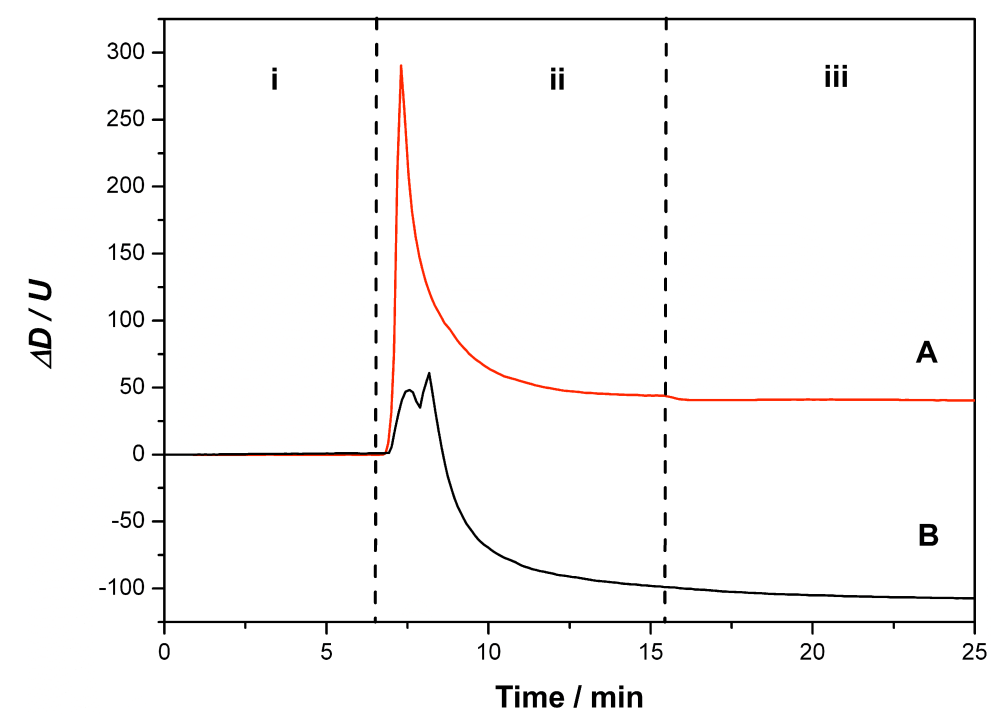

Figure S16. Dissipation change to $3^{\text {rd }}$ overtone when the tristearin coated sensor was exposed to: i) 0-7 minutes, water is used for both sensors to obtain a stable and flat baseline; ii) 7-16 minutes, $\mathrm{G}_{1} \mathrm{C}_{10} / \mathrm{ND} 97$ colloid and $\mathrm{G}_{1} \mathrm{C}_{10}$ solution were used for sensor $\mathrm{A}$ and $\mathrm{B}$ respectively, to remove tristearin lipid; iii) 16-25 minutes $\mathrm{G}_{1} \mathrm{C}_{10}$ solution was used for both sensors, to clean the QCM system. $\left[\mathrm{G}_{1} \mathrm{C}_{10}\right]=3.1 \mathrm{mmol} / \mathrm{L},[\mathrm{ND} 97]=0.1 \mathrm{~g} / \mathrm{L}$. 


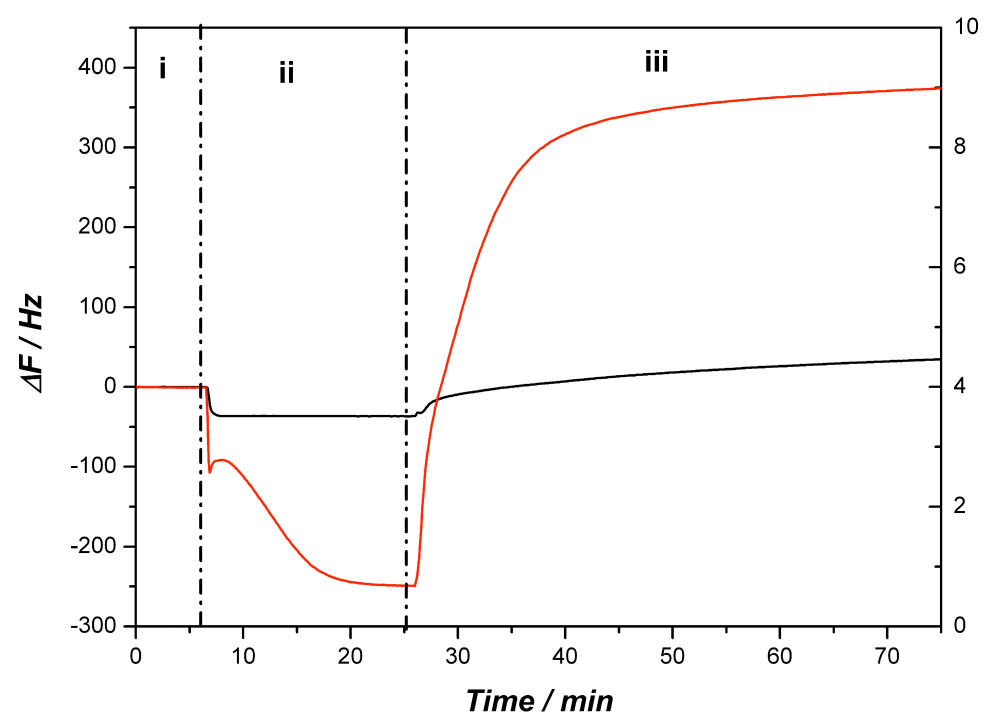

Figure S17. Frequency change to $3^{\text {rd }}$ overtone when the tristearin coated sensor was exposed to: i) 0-6 minutes, water is used for both sensors to obtain a stable and flat baseline; ii) 6-25 minutes, $\mathrm{G}_{2} \mathrm{C}_{10} / \mathrm{ND} 97$ colloid and $\mathrm{G}_{2} \mathrm{C}_{10}$ solution were used for sensor $\mathrm{A}$ and $\mathrm{B}$ respectively, to remove tristearin lipid; iii) 25-75 minutes SDBS solution was used for both sensors, to clean the $\mathrm{QCM}$ system. $[\mathrm{ND} 97]=0.1 \mathrm{~g} / \mathrm{L},\left[\mathrm{G}_{2} \mathrm{C}_{10}\right]=2.1 \mathrm{mmol} / \mathrm{L}$. $[\mathrm{SDBS}]=40 \mathrm{mmol} / \mathrm{L}$.

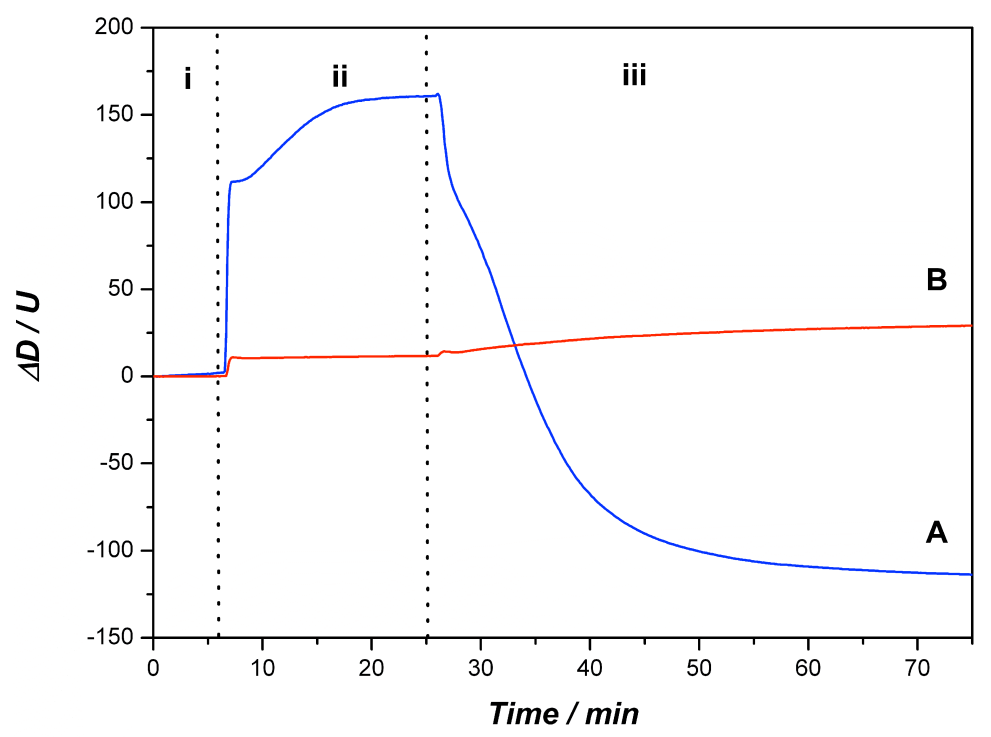

Figure S18. Dissipation change to $3^{\text {rd }}$ overtone when the tristearin coated sensor was exposed to: i) 0-6 minutes, water is used for both sensors to obtain a stable baseline; ii) 6-25 minutes, $\mathrm{G}_{2} \mathrm{C}_{10} / \mathrm{ND} 97$ colloid and $\mathrm{G}_{2} \mathrm{C}_{10}$ solution were used for sensor $\mathrm{A}$ and $\mathrm{B}$ respectively, to remove tristearin lipid; iii) 25-75 minutes SDBS solution was used for both sensors, to clean the $\mathrm{QCM}$ system. $[\mathrm{ND} 97]=0.1 \mathrm{~g} / \mathrm{L},\left[\mathrm{G}_{2} \mathrm{C}_{10}\right]=2.1 \mathrm{mmol} / \mathrm{L} .[\mathrm{SDBS}]=40 \mathrm{mmol} / \mathrm{L}$. 


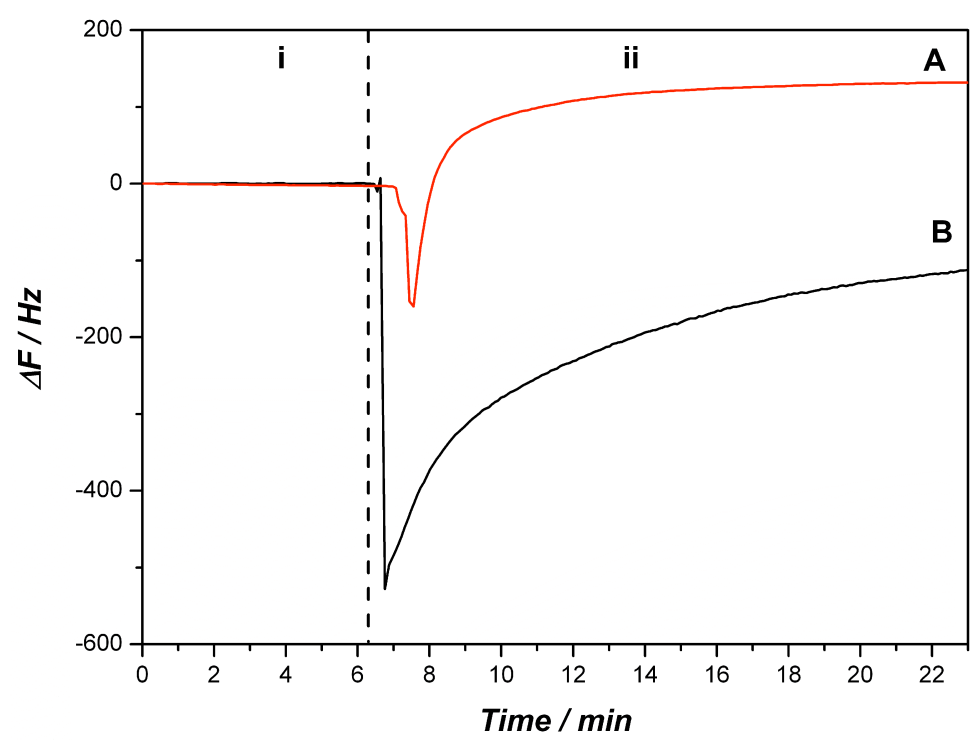

Figure S19. Frequency change to $3^{\text {rd }}$ overtone when the tristearin coated sensor was exposed to: i) 0-6 minutes, water is used for both sensors to obtain a stable baseline; ii) 6-23 minutes, DDAO/ND97 colloid and DDAO solution were used for sensor A and B respectively, to remove tristearin lipid. [ND97] $=0.1 \mathrm{~g} / \mathrm{L},[\mathrm{DDA} 0]=40 \mathrm{mmol} / \mathrm{L}$.

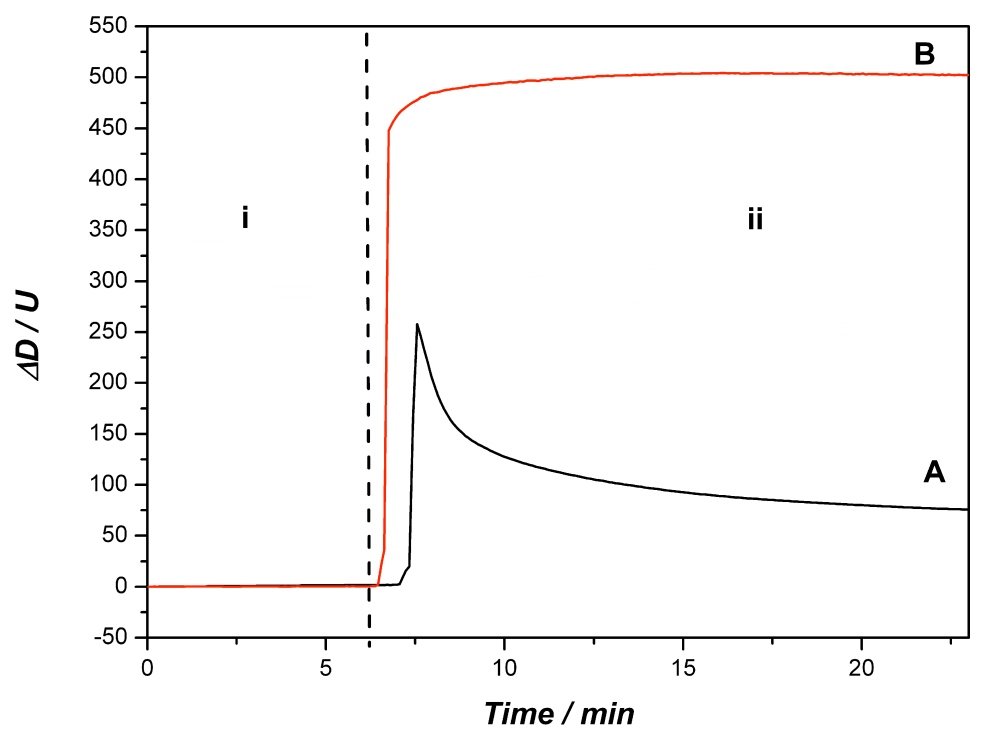

Figure S20. Dissipation change to $3^{\text {rd }}$ overtone when the tristearin coated sensor exposure to buffers: i) 0-6 minutes, water is used for both sensors to obtain a stable baseline; ii) 6-23 minutes, DDAO/ND97 colloid and DDAO solution were used for sensor $\mathrm{A}$ and $\mathrm{B}$ respectively, to remove tristearin lipid. $[\mathrm{ND} 97]=0.1 \mathrm{~g} / \mathrm{L},[\mathrm{DDA} 0]=40 \mathrm{mmol} / \mathrm{L}$. 


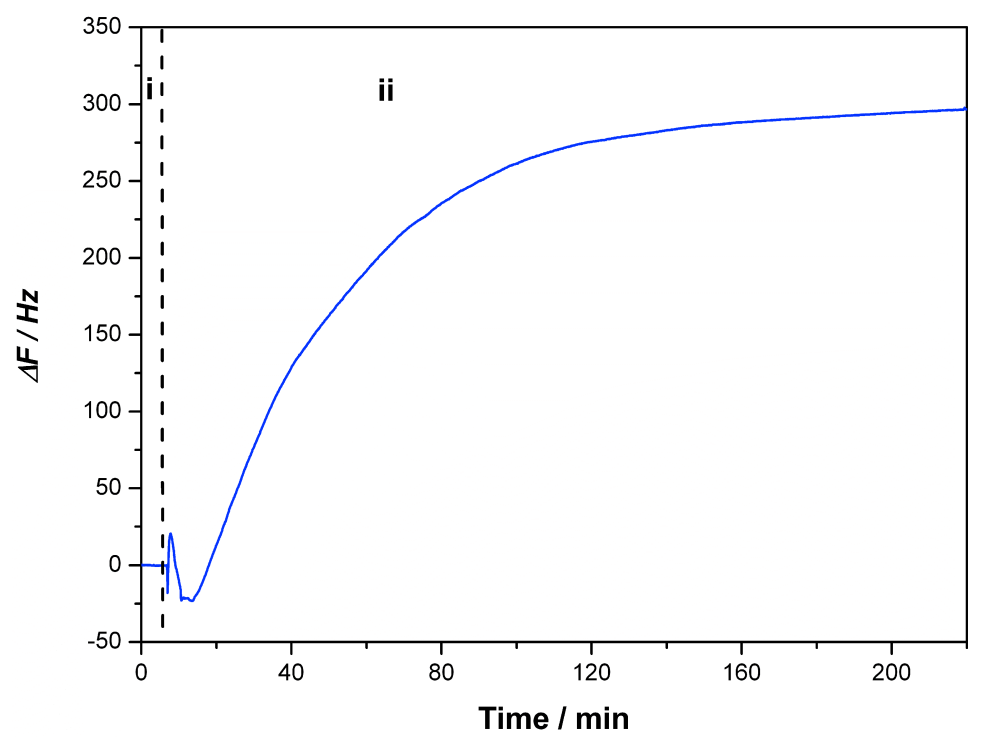

Figure S21. Frequency change to $3^{\text {rd }}$ overtone when the tristearin coated sensor was exposed to: i) 0-7 minutes, water was used to obtain a stable baseline; ii) 7-220 minutes, $\mathrm{NFE}_{10}$ nonionic surfactant was used for removal of tristearin lipid. $\left[\mathrm{NFE}_{10}\right]=0.15 \mathrm{wt} . \%$.

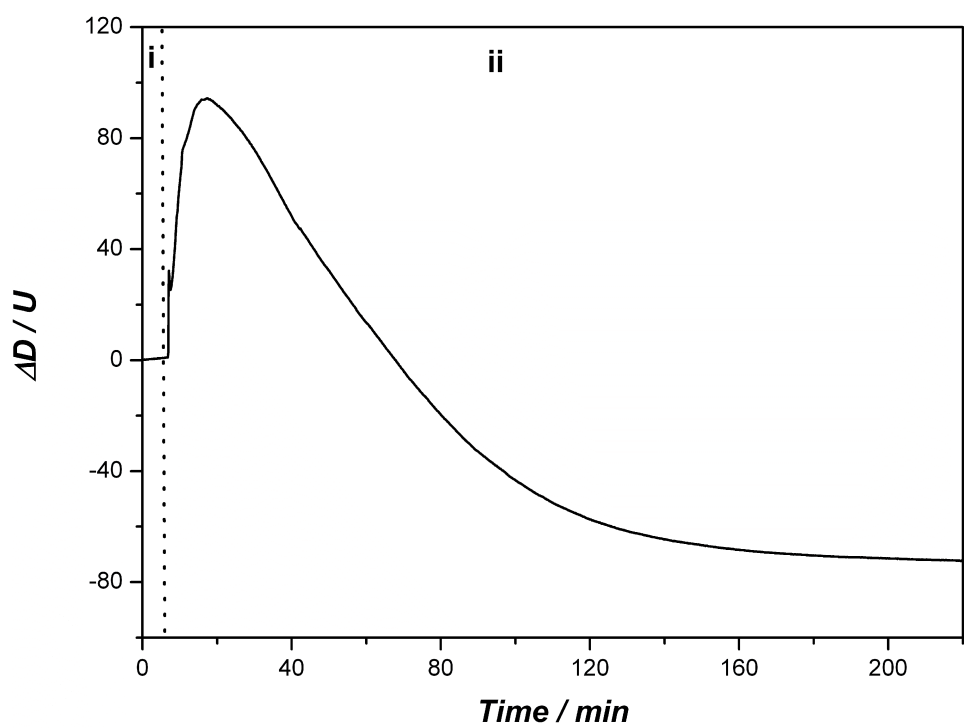

Figure S22. Dissipation change to $3^{\text {rd }}$ overtone when the tristearin coated sensor was exposed to: i) 0-7 minutes, water was used to obtain a stable baseline; ii) 7-220 minutes, $\mathrm{NFE}_{10}$ non-ionic surfactant was used for removal of tristearin lipid. $\left[\mathrm{NFE}_{10}\right]=0.15 \mathrm{wt} . \%$. 


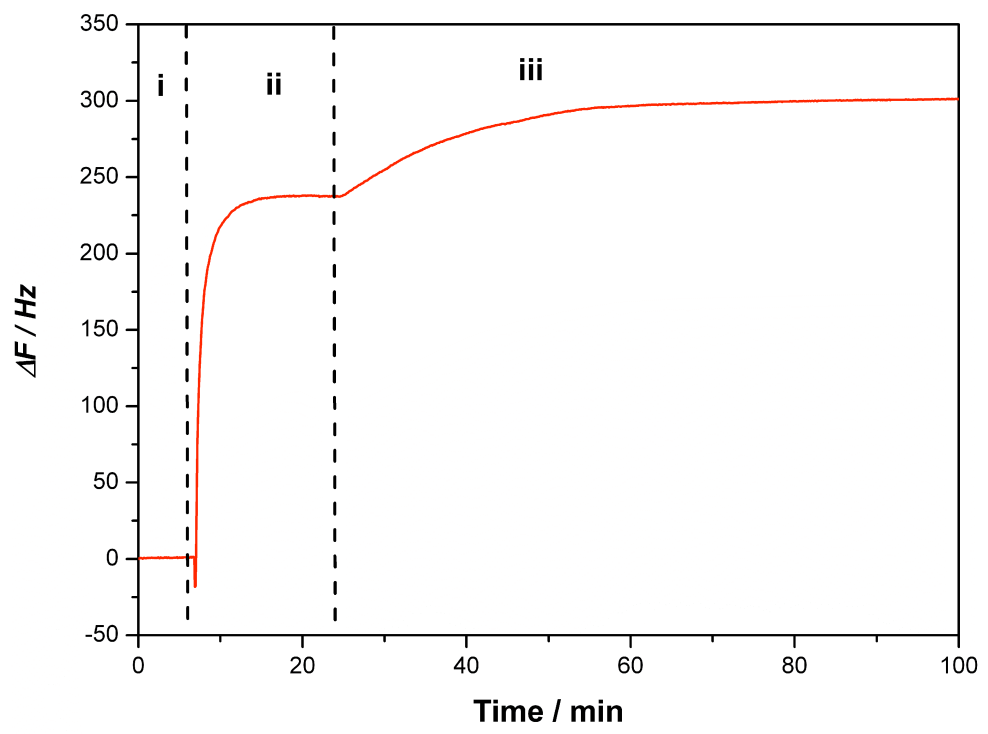

Figure S23. Frequency change to $3^{\text {rd }}$ overtone when the tristearin coated sensor was exposed to: i) 0-7 minutes, water was used to obtain a stable baseline; ii) 7-25 minutes, ND97/NFE 10 colloid was used for removal of tristearin lipid; and iii) 25-100 minutes, $\mathrm{NFE}_{10}$ solution was used for the purpose of cleaning. $\left[\mathrm{NFE}_{10}\right]=0.15 \mathrm{wt} . \%$, [ND97] $=0.1 \mathrm{~g} / \mathrm{L}$.

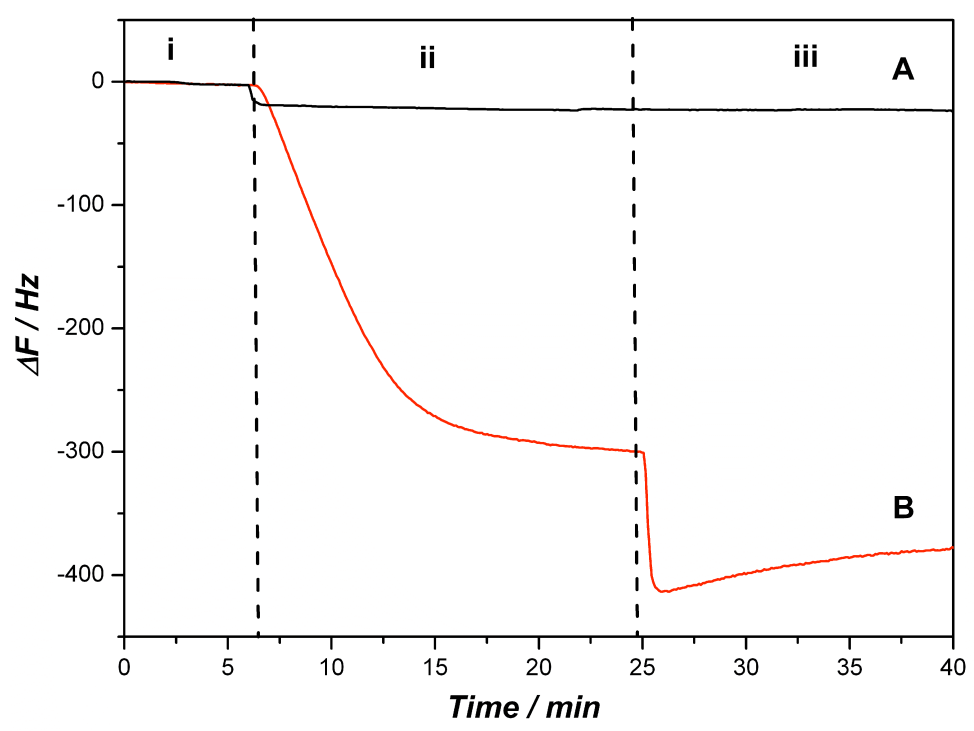

Figure S24. Frequency change to $3^{\text {rd }}$ overtone when the tristearin coated sensor was exposed to: i) 0-6 minutes, water was used to obtain a stable baseline; ii) 6-25 minutes, ND97 suspension was used to deposit nanoparticles on the lipid layer for sensor B, and Brij ${ }^{\circledR} 35$ solution was used for lipid removal for sensor A; and iii) 25-40 minutes, Brij ${ }^{\circledR} 35$ solution was used for both sensors. [Brij $\left.{ }^{\circledR} 35\right]=8 \mathrm{~g} / \mathrm{L},[\mathrm{ND} 97]=0.1 \mathrm{~g} / \mathrm{L}$. 


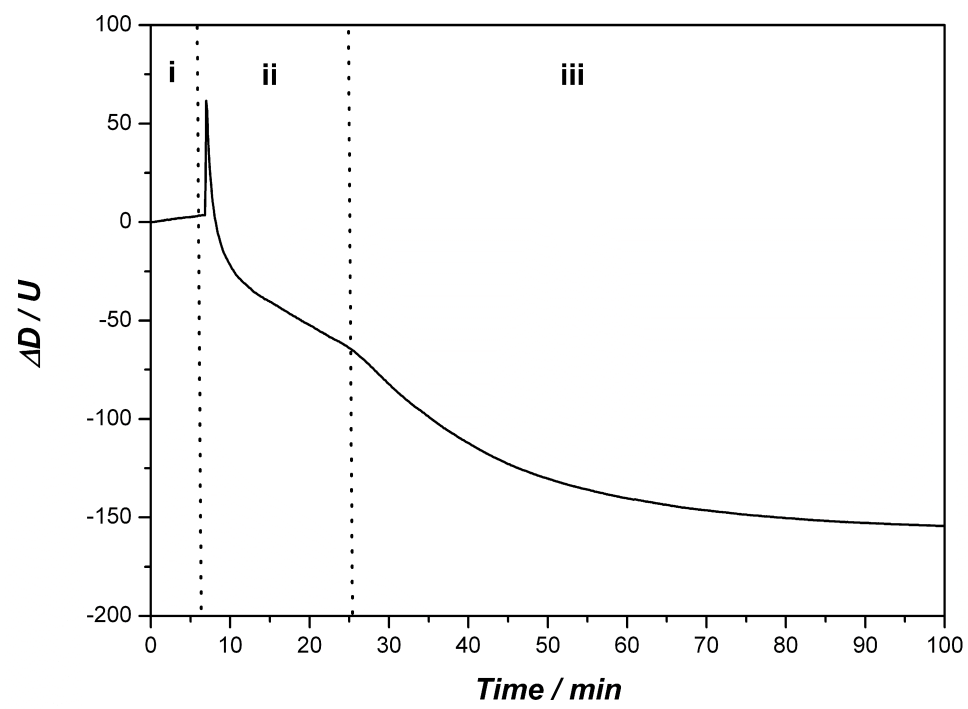

Figure S25. Dissipation change to $3^{\text {rd }}$ overtone when the tristearin coated sensor was exposed to: i) 0-7 minutes, water was used to obtain a stable baseline; ii) 7-25 minutes, ND97/NFE 10 colloid was used for removal of tristearin lipid; and iii) 25-100 minutes, $\mathrm{NFE}_{10}$ solution was used for the purpose of cleaning. $\left[\mathrm{NFE}_{10}\right]=0.15 \mathrm{wt} \%$, [ND97] $=0.1 \mathrm{~g} / \mathrm{L}$.

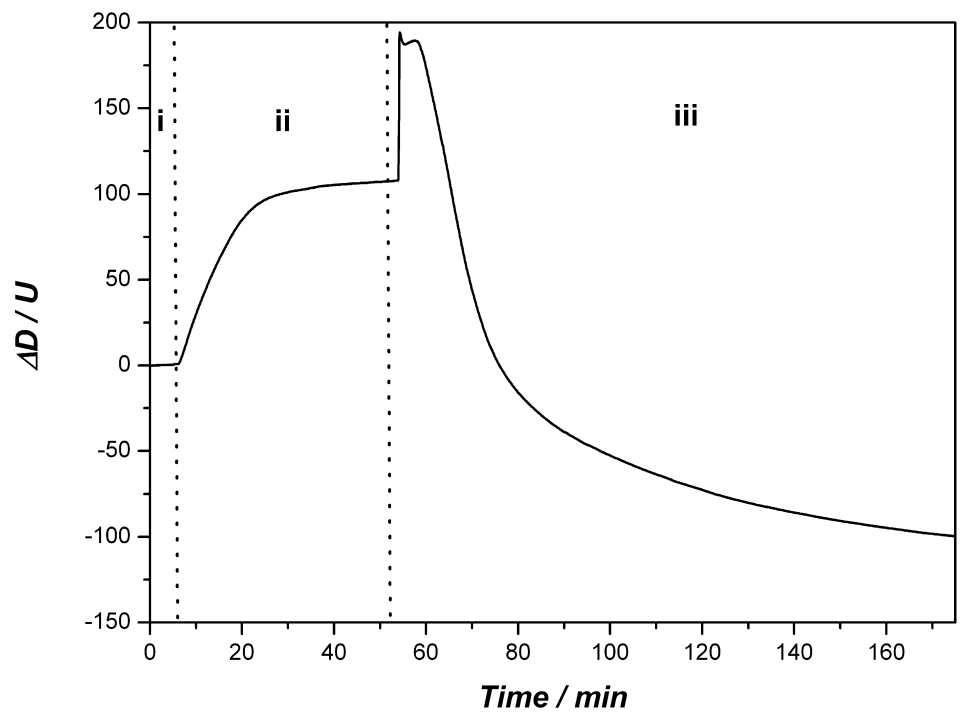

Figure S26. Dissipation change to $3^{\text {rd }}$ overtone when the tristearin coated sensor exposed to: i) 0-7 minutes, water is used to obtain a stable baseline; ii) 7-52 minutes, ND97 suspension is used to deposit particles on lipid; and iii) 52-175 minutes SDBS solution was used for lipid removal. $[\mathrm{SDBS}]=40 \mathrm{mmol} / \mathrm{L},[\mathrm{ND} 97]=0.1 \mathrm{~g} / \mathrm{L}$. 


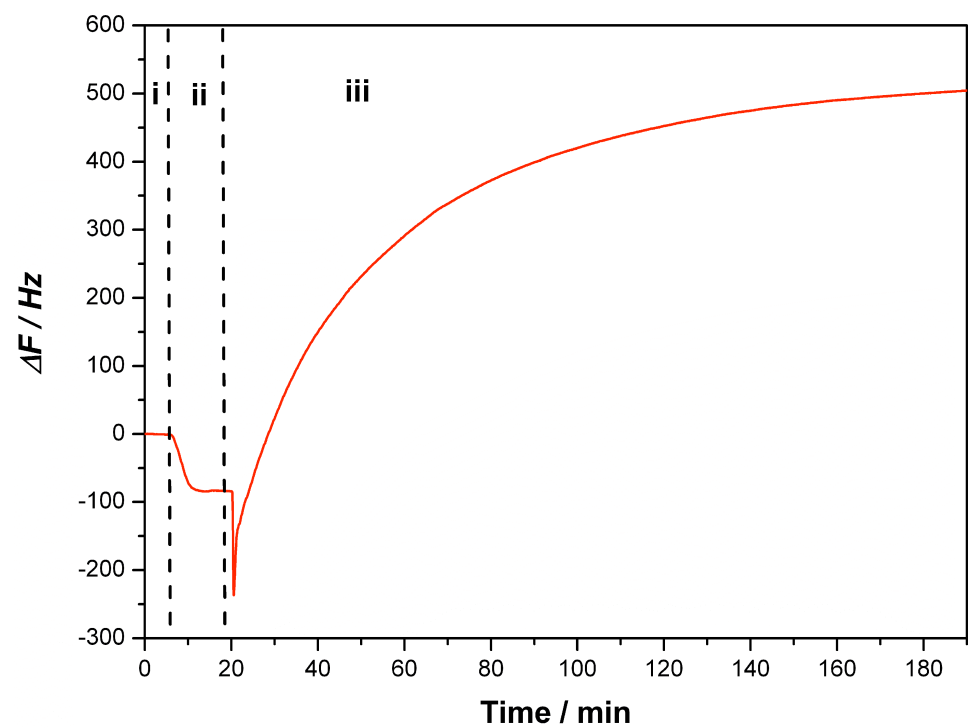

Figure S27. Frequency change to $3^{\text {rd }}$ overtone when the tristearin coated sensor was exposed to: i) 0-7 minutes, water is used to obtain a stable baseline; ii) 7-18 minutes, suspension of nanoparticle 2 is used to deposit particles on lipid; iii) 18-190 minutes SDBS solution was used for lipid removal. $[\mathrm{SDBS}]=40 \mathrm{mmol} / \mathrm{L},[2]=0.1 \mathrm{~g} / \mathrm{L}$.

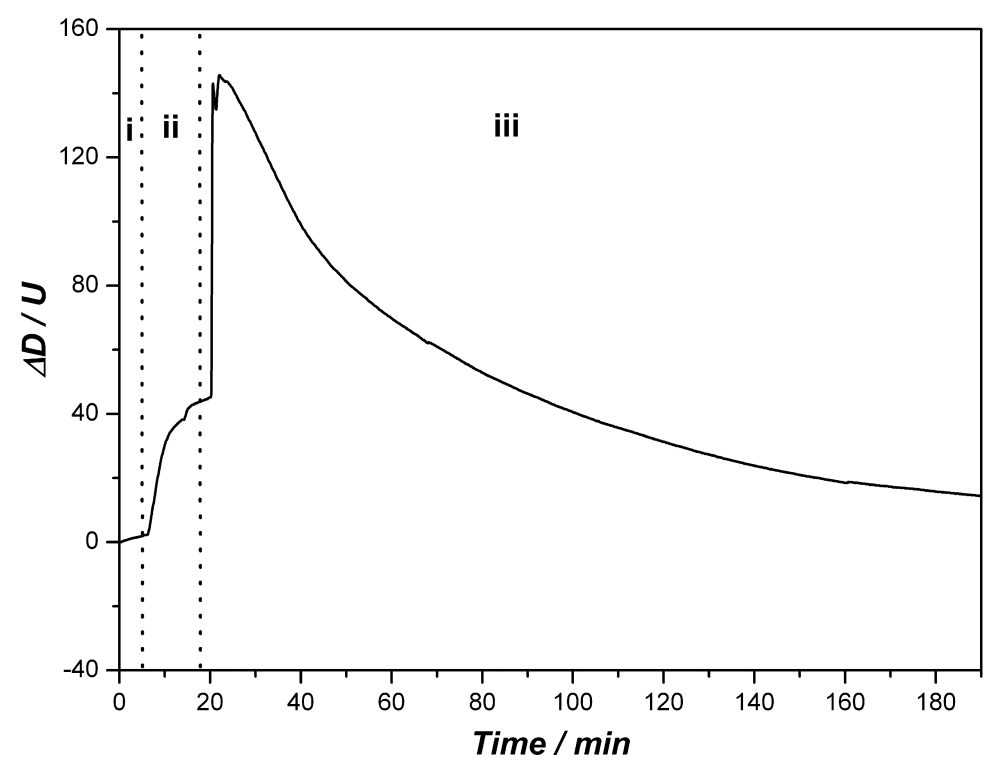

Figure S28. Dissipation change to $3^{\text {rd }}$ overtone when the tristearin coated sensor was exposed to: i) 0-7 minutes, water is used to obtain a stable baseline; ii) 7-18 minutes, suspension of nanoparticle 2 is used to deposit particles on lipid; iii) 18-190 minutes SDBS solution was used for lipid removal. $[\mathrm{SDBS}]=40 \mathrm{mmol} / \mathrm{L},[2]=0.1 \mathrm{~g} / \mathrm{L}$. 


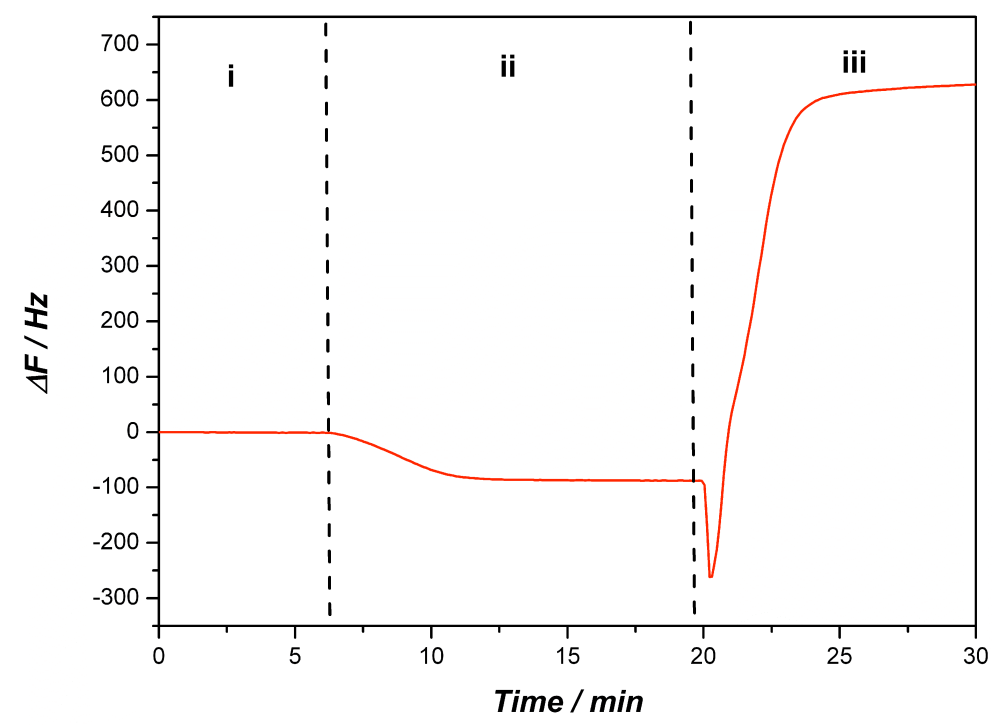

Figure S29. Frequency change to $3^{\text {rd }}$ overtone when the tristearin coated sensor was exposed to: i) 0-7 minutes, water is used to obtain a stable baseline; ii) 7-20 minutes, suspension of nanoparticle 2 is used to deposit particles on lipid; iii) 20-30 minutes $\mathrm{G}_{1} \mathrm{C}_{10}$ solution was used for lipid removal. $\left[\mathrm{G}_{1} \mathrm{C}_{10}\right]=3.1 \mathrm{mmol} / \mathrm{L},[2]=0.1 \mathrm{~g} / \mathrm{L}$.

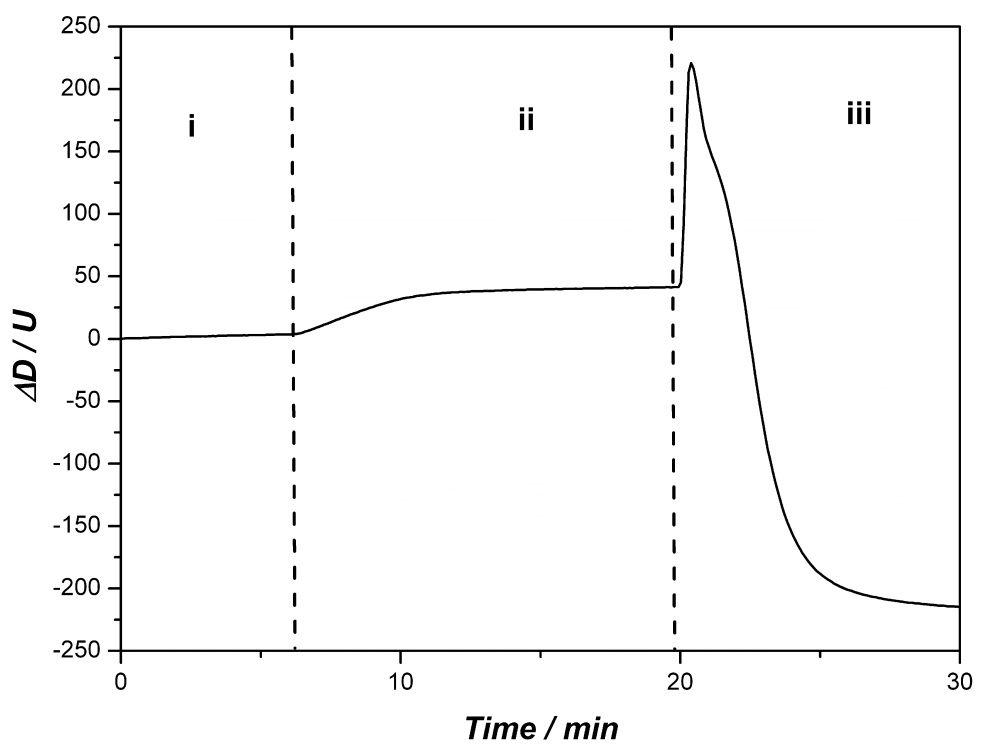

Figure S30. Dissipation change to $3^{\text {rd }}$ overtone when the tristearin coated sensor was exposed to: i) 0-7 minutes, water is used to obtain a stable baseline; ii) 7-20 minutes, suspension of nanoparticle 2 is used to deposit particles on lipid; iii) 20-30 minutes $G_{1} C_{10}$ solution was used for lipid removal. $\left[\mathrm{G}_{1} \mathrm{C}_{10}\right]=3.1 \mathrm{mmol} / \mathrm{L},[2]=0.1 \mathrm{~g} / \mathrm{L}$. 


\section{S6. QCM-D data for lipid removal by SDBS at different concentration at $25^{\circ} \mathrm{C}$ (frequency and dissipation change to $3^{\text {rd }}$ overtone measured by QCM-D)}

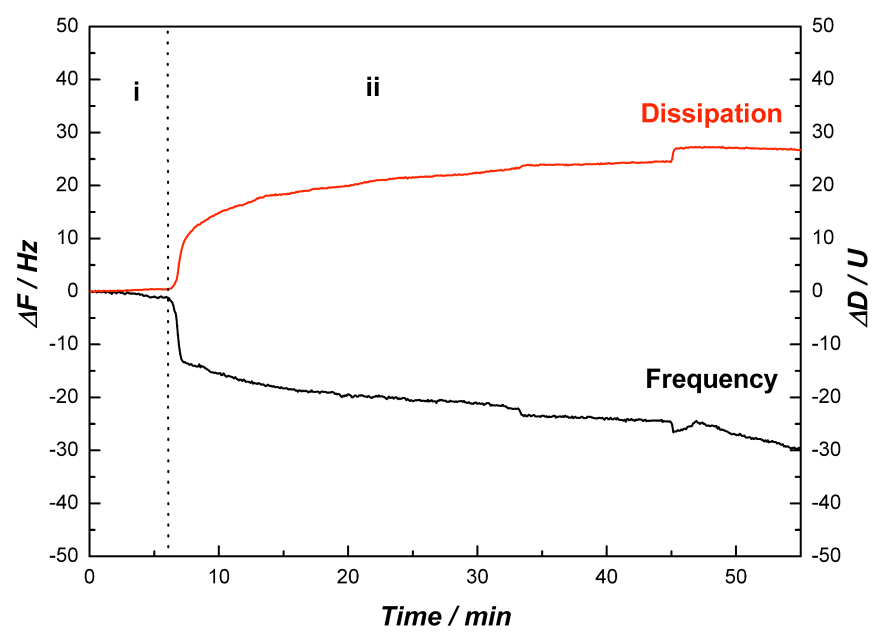

Figure S31. Frequency and dissipation changes on $3^{\text {rd }}$ overtone when tristearin lipid coated sensor exposure to buffers: i) 0-6 minuts, water was used to get a stable and flat baseline; and ii) 6-55 minutes, SDBS solution was used for removing lipid. $[\mathrm{SDBS}]=1 \mathrm{mmol} / \mathrm{L}, \mathrm{T}=25^{\circ} \mathrm{C}$. No desorption was observed at concentration below the critical micelle concentration (CMC, $1.2 \mathrm{mmol} / \mathrm{L})$.

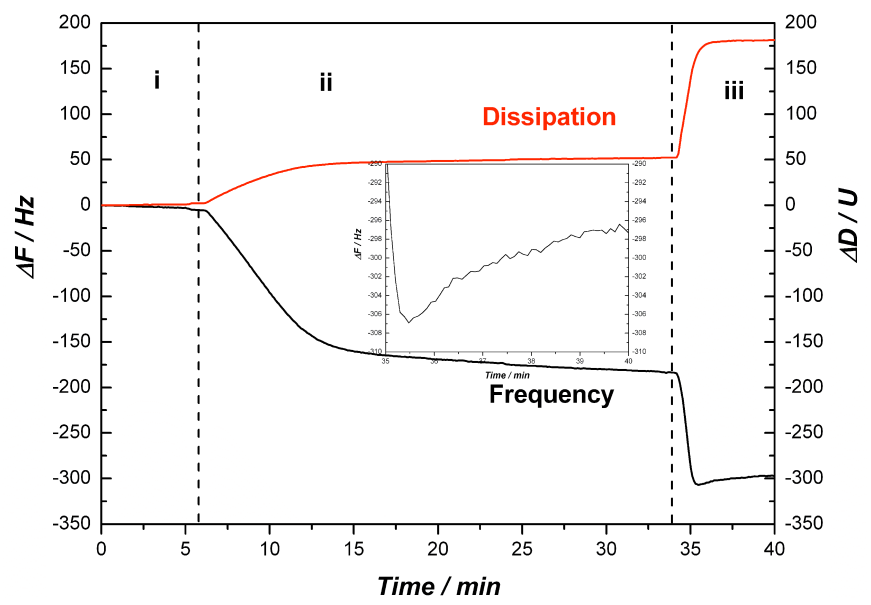

Figure S32. Frequency and dissipation changes to $3^{\text {rd }}$ overtone when tristearin lipid coated sensor is exposed to: i) 0-6 minutes, water was used to get a stable and flat baseline; ii) 6-33 minutes, ND97 was used to deposit nanoparticles on lipid layer, and iii) 33-40 minutes, SDBS solution was used for removing lipid. [ND97] $=0.1 \mathrm{~g} / \mathrm{L},[\mathrm{SDBS}]=1 \mathrm{mmol} / \mathrm{L}, \mathrm{T}=$ $25{ }^{\circ} \mathrm{C}$. A very limited desorption was observed with a $10 \mathrm{~Hz}$ increase in Frequency, which was achieved after 5 minutes. There is no change observed to dissipation, since the amount of lipid removal is too small to affect the viscoelasticity property of lipid layer. 


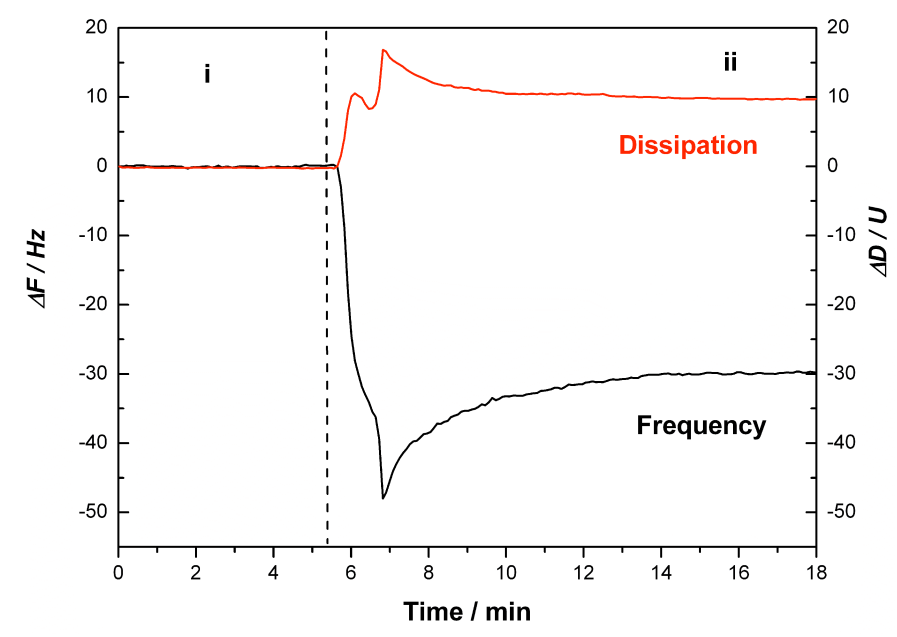

Figure S33. Frequency and dissipation changes to $3^{\text {rd }}$ overtone when tristearin lipid coated sensor is exposed to: i) 0-5 minutes, water is used for a flat baseline; ii) 5-18 minutes, 20 $\mathrm{mmol} / \mathrm{L}$ SDBS was used. $\mathrm{T}=25^{\circ} \mathrm{C}$. Initial adsorption of surfactants caused a decrease in frequency and an increase in dissipation, and the following desorption resulted in an increase in frequency and a decrease in dissipation. In fact, the 'desorption' observed on QCM-D is the combine effect of lipid-surfactants aggregate leaving from lipid layer and the adsorption of surfactant from bulk solution. Thus, the frequency increase calculated from the lowest point $R$ is attributed to the net removal of lipid. The lipid removal of $c a 19 \mathrm{~Hz}$ was achieved in 7 minutes.

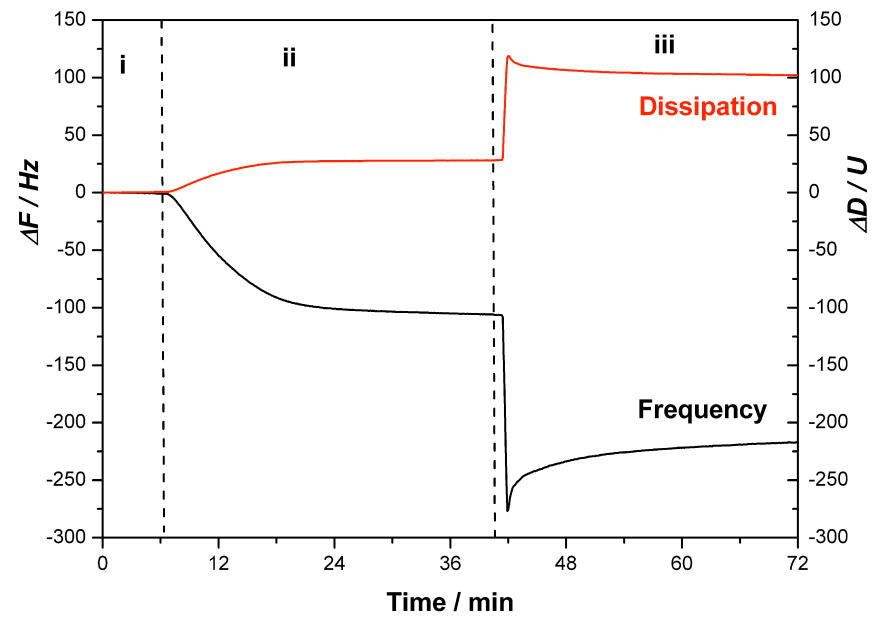

Figure S34. Frequency and dissipation changes to $3^{\text {rd }}$ overtone when tristearin lipid coated sensor exposure to buffers: i) 0-5 minutes, water is used for a flat baseline; ii) 5-19 minutes, $0.1 \mathrm{~g} / \mathrm{L}$ ND97 was used to deposit nanoparticles on the lipid surface; and iii) $20 \mathrm{mmol} / \mathrm{L}$ SDBS was used. $\mathrm{T}=25^{\circ} \mathrm{C}$. The maximum desorption was observed to be $60 \mathrm{~Hz}$, and it was achieved after around 20 minutes. However, the decrease in dissipation induced by desorption was relatively small, indicating that nanoparticles remained on the lipid layer at end of lipid removing process. Thus, this maximum desorption calculated from the lowest point was attributed to the total lipid removal. 


\section{S7. QCM-D data for lipid removal at $25^{\circ} \mathrm{C}$ by $40 \mathrm{mmol} / \mathrm{L}$ anionic surfactant SDBS in the presence of nanoparticles with various zeta potential (frequency and dissipation change to $3^{\text {rd }}$ overtone measured by QCM-D).}

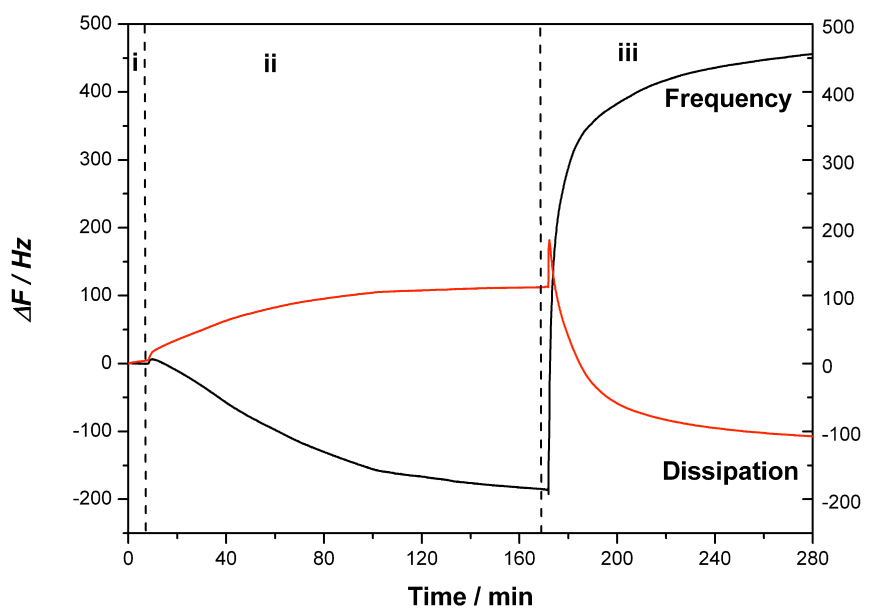

Figure S35. Frequency and dissipation changes of $3^{\text {rd }}$ overtone after exposure of the tristearin coated sensor to: i) 0-7 minutes, water was used for baseline; ii) 7-170 minutes, colloid of nanoparticle 3 was used to deposit nanoparticles on the surface; and iii) 170-280 minutes, SDBS solution was used for lipid removal. [3] $=0.1 \mathrm{~g} / \mathrm{L},[\mathrm{SDBS}]=40 \mathrm{mmol} / \mathrm{L}, \mathrm{T}=25^{\circ} \mathrm{C}$. In the presence of 1 nanoparticles with zeta potential of $26.1 \mathrm{mV}$, the lipid removal $R$ of $650 \mathrm{~Hz}$ was achieved after 110 minutes. Note that the maximum removal possibly is over 650 $\mathrm{Hz}$, as the frequency remains increasing after exposure to SDBS solution for over 110 minutes.

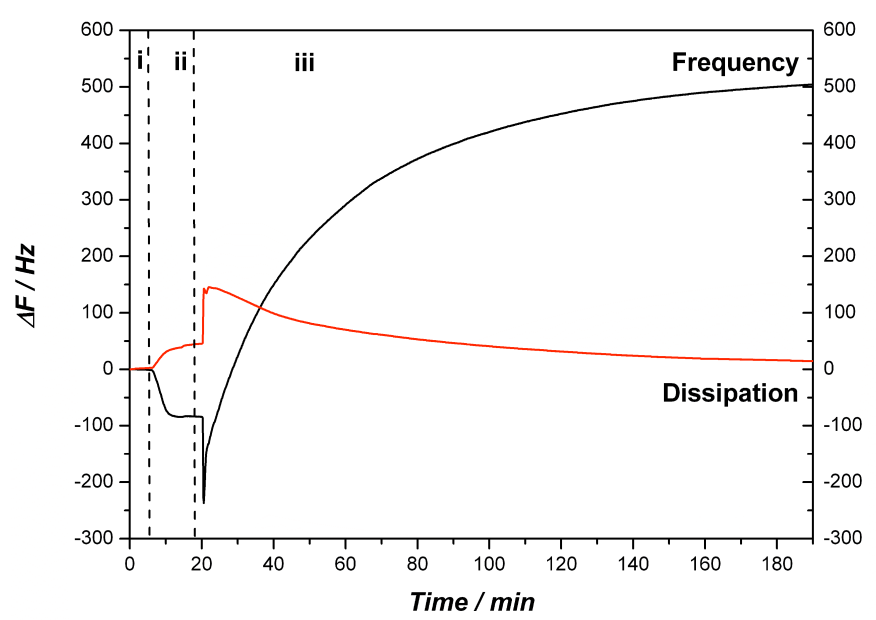

Figure S36. Frequency and dissipation changes of $3^{\text {rd }}$ overtone after exposure of the tristearin lipid coated sensor to: i) 0-7 minutes, water was used for baseline; ii) 7-20 minutes, suspension of nanoparticle 2 was used to deposit nanoparticles on the lipid layer; and iii) 20190 minutes, SDBS $40 \mathrm{mmol} / \mathrm{L}$. In the presence of 2 nanoparticles with zeta potential of $41.5 \mathrm{mV}$, the lipid removal $R$ was observed to $740 \mathrm{~Hz}$ and achieved after 170 minutes respectively. $[2]=0.1 \mathrm{~g} / \mathrm{L},[\mathrm{SDBS}]=40 \mathrm{mmol} / \mathrm{L}, \mathrm{T}=25^{\circ} \mathrm{C}$. 


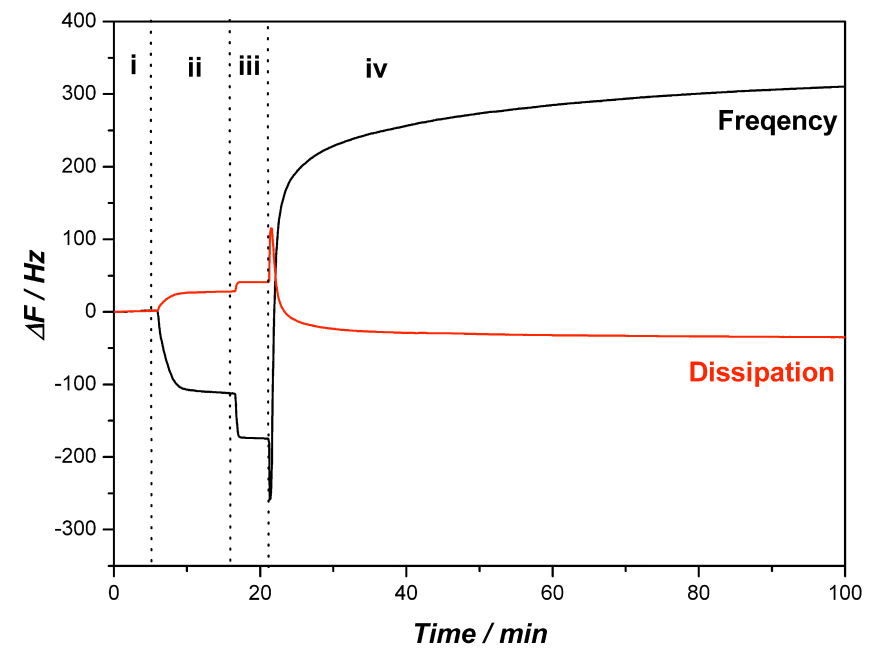

Figure S37. Frequency changes of $3^{\text {rd }}$ overtone after exposure of the tristearin coated sensor to: i) 0-7 minutes, water was used for baseline; ii) 7-16 minutes, suspension of nanoparticles 2 was used to deposit nanoparticles on the lipid layer; iii) 16-21 minutes, colloid of nanoparticle 1 was used to neutralize the positive charged surface of nanoparticles, and iv) 21-100 minutes, SDBS was used for cleaning. In the presence of both positively charged hydrogenated 2 and negatively charged oxidised nanoparticle 1, the lipid removal of $570 \mathrm{~Hz}$ was achieved after exposure to SDBS solution for around 65 minutes. $[1]=[2]=0.1 \mathrm{~g} / \mathrm{L}$, $[\mathrm{SDBS}]=40 \mathrm{mmol} / \mathrm{L}, \mathrm{T}=25^{\circ} \mathrm{C}$. 
S8. QCM-D data for lipid removal at $25^{\circ} \mathrm{C}$ by by non-ionic surfactant decyl $\beta$-Dglucopyranoside $\left(\mathrm{G}_{1} \mathrm{C}_{10}\right)$ in the presence of nanoparticles with various zeta potential (frequency and dissipation change to $3^{\text {rd }}$ overtone).

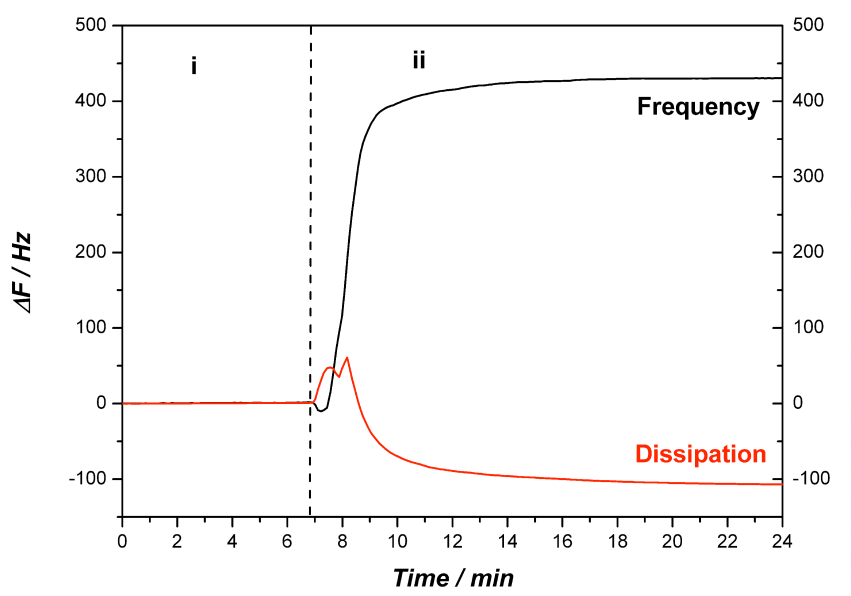

Figure S38. Frequency changes to $3^{\text {rd }}$ overtone after exposure the tristearin coated sensor to: i) 0-7 minutes, water; ii) 7-24 minutes, $\mathrm{G}_{1} \mathrm{C}_{10}$ solution $3.1 \mathrm{mmol} / \mathrm{L}$. Without any nanoparticles, the lipid removal of $440 \mathrm{~Hz}$ was achieved after exposure $\mathrm{G}_{1} \mathrm{C}_{10}$ solution for 8 minutes. $\mathrm{T}=25^{\circ} \mathrm{C}$.

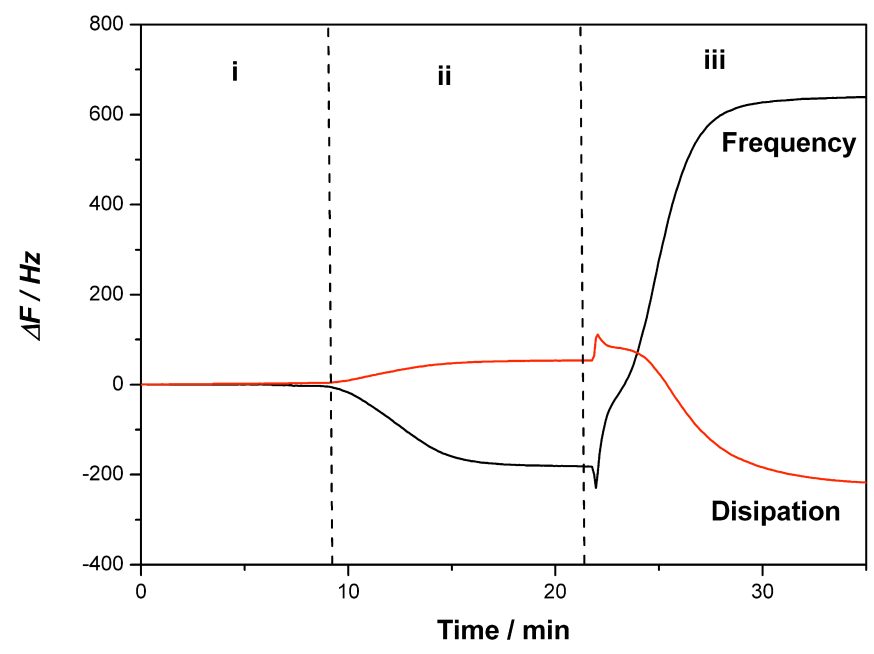

Figure S39. Frequency changes to $3^{\text {rd }}$ overtone after exposure of the tristearin coated sensor to: i) 0-8 minutes, water; ii) 8-22 minutes, ND97 suspension was used to deposit nanoparticles on lipid layer; iii) 22-35 minutes, $\mathrm{G}_{1} \mathrm{C}_{10}$ solution was used for lipid removing. $[\mathrm{ND} 97]=0.1 \mathrm{~g} / \mathrm{L},\left[\mathrm{G}_{1} \mathrm{C}_{10}\right]=3.1 \mathrm{mmol} / \mathrm{L}, \mathrm{T}=25^{\circ} \mathrm{C}$. The maximum lipid removal of $865 \mathrm{~Hz}$ was achieved within 8 minutes after exposure to $\mathrm{G}_{1} \mathrm{C}_{10}$ solution, in the presence of ND97 nanoparticles with a zeta potential of $c a 15 \mathrm{mV}$. 


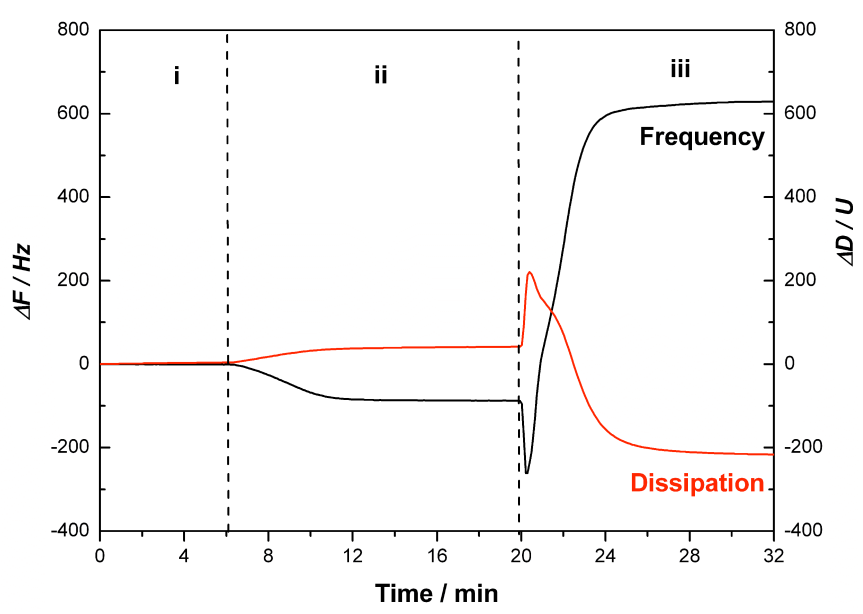

Figure S40. Frequency changes to $3^{\text {rd }}$ overtone after exposure the tristearin coated sensor to buffers: i) 0-7 minutes, water was used for baseline; ii) 7-20 minutes, suspension of nanoparticle 2 was used to deposit nanoparticles on the lipid, and iii) $20-32, \mathrm{G}_{1} \mathrm{C}_{10}$ solution was used for lipid removing. In the presence of nanoparticles 2 with zeta potential of 41.5 $\mathrm{mV}$, the lipid removal of $900 \mathrm{~Hz}$ was achieved for exposure to $\mathrm{G}_{1} \mathrm{C}_{10}$ for 8 minutes. [2] $=0.1$ $\mathrm{g} / \mathrm{L},\left[\mathrm{G}_{1} \mathrm{C}_{10}\right]=3.1 \mathrm{mmol} / \mathrm{L}, \mathrm{T}=25^{\circ} \mathrm{C}$.

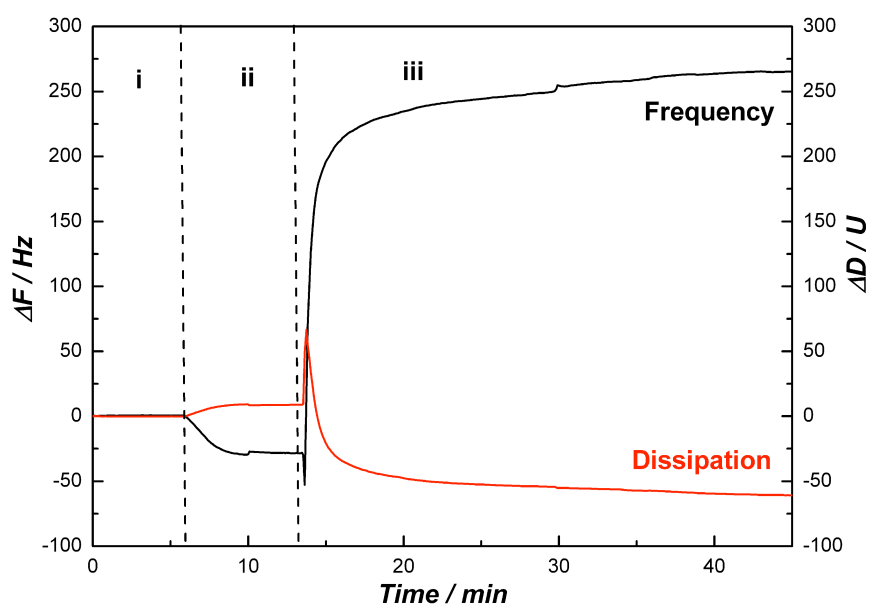

Figure S41. Frequency changes to $3^{\text {rd }}$ overtone after exposure of the tristearin coated sensor to: i) 0-7 minutes, water; ii) 7-13 minutes, suspension of nanoparticle 4 was used to deposit nanoparticles on lipid layer, and iii) $13-45, \mathrm{G}_{1} \mathrm{C}_{10}$ solution was used for lipid removing. In the presence of nanoparticle 4 with a zeta potential of $48.1 \mathrm{mV}$, the lipid removal of $320 \mathrm{~Hz}$ was achieved for exposure to $\mathrm{G}_{1} \mathrm{C}_{10}$ for 27 minutes. [4] $=0.1 \mathrm{~g} / \mathrm{L},\left[\mathrm{G}_{1} \mathrm{C}_{10}\right]=3.1 \mathrm{mmol} / \mathrm{L}, \mathrm{T}=$ $25{ }^{\circ} \mathrm{C}$. 
S9. QCM-D data for lipid removal at $25^{\circ} \mathrm{C}$ by cationic surfactant CTAB in the presence of nanoparticles exhibiting various zeta potentials (frequency and dissipation change to $3^{\text {rd }}$ overtone).

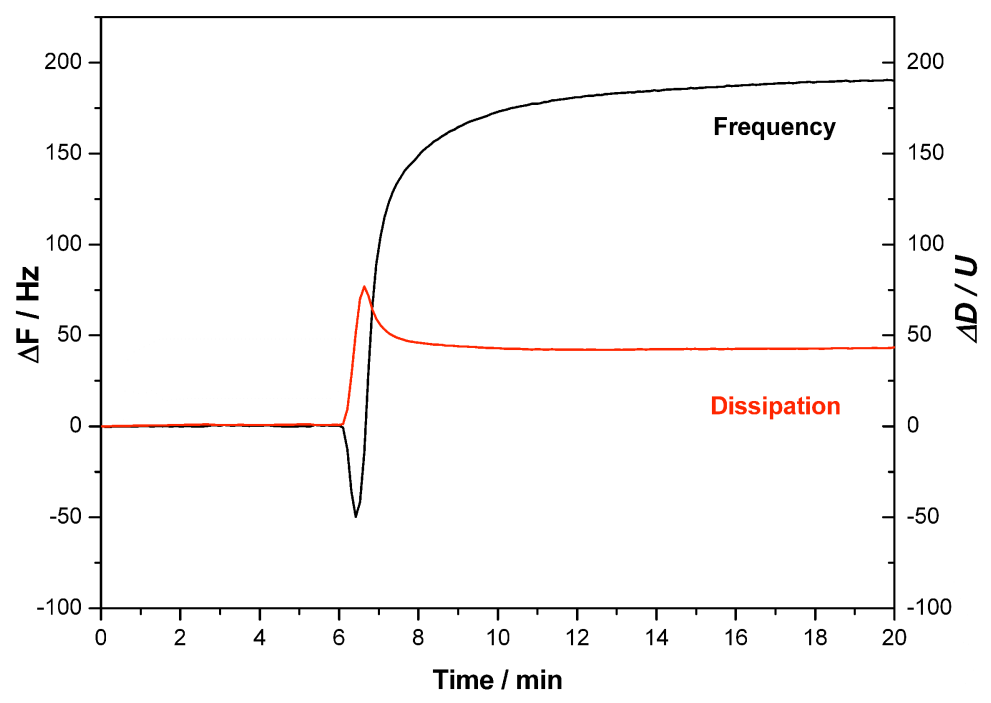

Figure S42. Frequency changes to $3^{\text {rd }}$ overtone after exposure of the tristearin coated sensor to: i) 0-6 minutes, water; ii) 6-20 minutes, $\mathrm{CTAB}$ solution. $[\mathrm{CTAB}]=2 \mathrm{mmol} / \mathrm{L}, \mathrm{T}=25^{\circ} \mathrm{C}$. The maximum lipid removal of $240 \mathrm{~Hz}$ was achieved after exposure to CTAB solution for $c a$. 12 minutes.

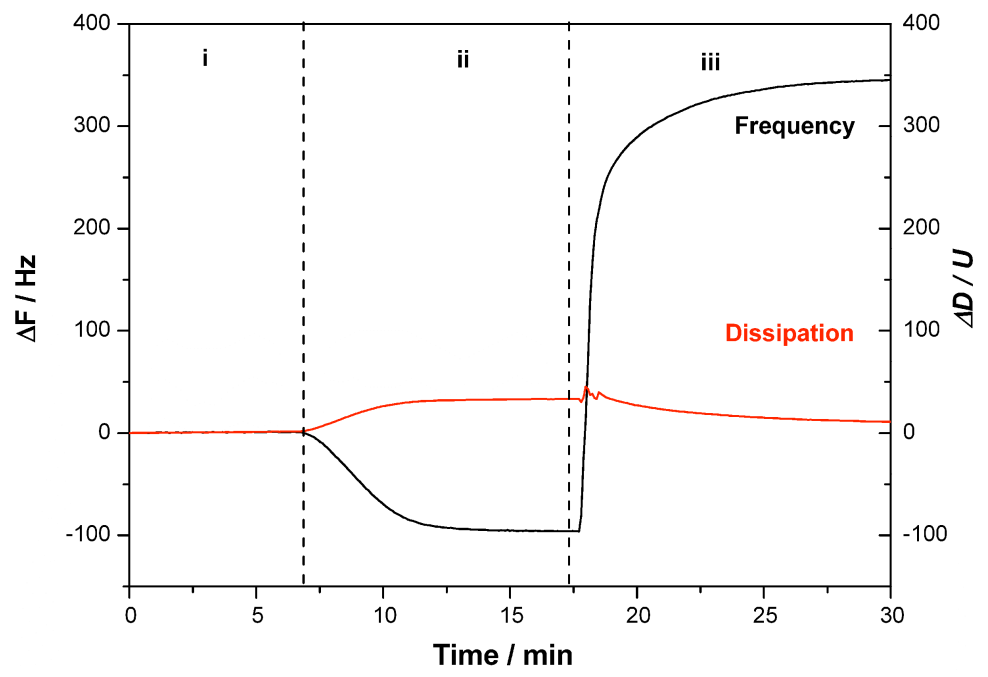

Figure S43. Frequency and dissipation changes to $3^{\text {rd }}$ overtone after exposure of the tristearin coated sensor to: i) 0-7 minutes, water; ii) 6-17 minutes, ND97 was used to deposit nanoparticles; and iii) 17-30 minutes, $2 \mathrm{mmol} / \mathrm{L} \mathrm{CTAB}$ solution was used for cleaning. The maximum lipid removal of $392 \mathrm{~Hz}$ was achieved after exposure to CTAB solution for $c a .50$ minutes. $[\mathrm{ND} 97]=0.1 \mathrm{~g} / \mathrm{L},[\mathrm{CTAB}]=2 \mathrm{mmol} / \mathrm{L}, \mathrm{T}=25^{\circ} \mathrm{C}$. 


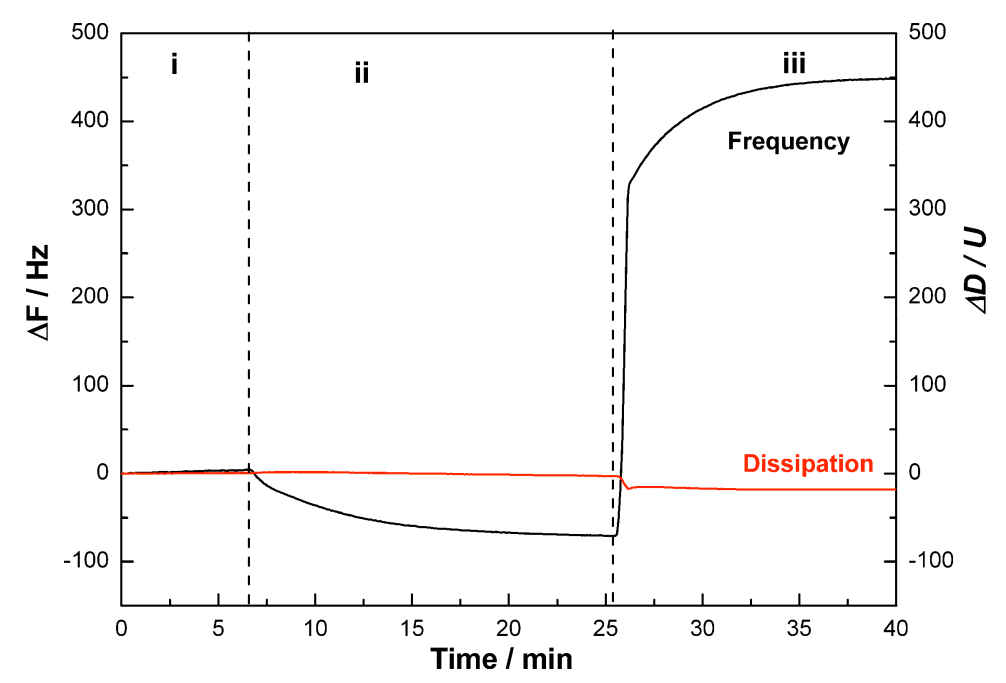

Figure S44. Frequency and dissipation changes to $3^{\text {rd }}$ overtone after exposure of the tristearin coated sensor to: i) 0-7 minutes, water; ii) 6-25 minutes, suspension of 2 was used to deposit nanoparticles; and iii) 25-40 minutes, $2 \mathrm{mmol} / \mathrm{L} \mathrm{CTAB}$ solution was used for cleaning. The maximum lipid removal of $392 \mathrm{~Hz}$ was achieved after exposure to CTAB solution for $\mathrm{ca} 50$ minutes. $[2]=0.1 \mathrm{~g} / \mathrm{L},[\mathrm{CTAB}]=2 \mathrm{mmol} / \mathrm{L}, \mathrm{T}=25^{\circ} \mathrm{C}$.

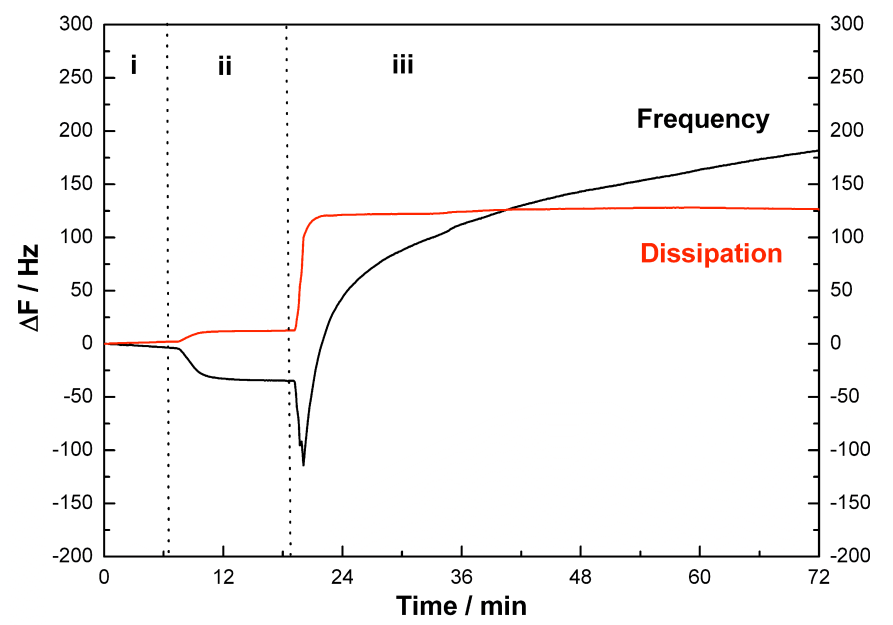

Figure S45. Frequency and dissipation changes on $3^{\text {rd }}$ overtone after exposure of the tristearin coated sensor to: i) 0-7 minutes, water; ii) 6-19 minutes, suspension of 4 was used to deposit nanoparticles; and iii) 19-72 minutes, $2 \mathrm{mmol} / \mathrm{L}$ CTAB solution was used for cleaning. The maximum lipid removal of $300 \mathrm{~Hz}$ was achieved after exposure to CTAB solution for $c a 53$ minutes. [4] $=0.1 \mathrm{~g} / \mathrm{L},[\mathrm{CTAB}]=2 \mathrm{mmol} / \mathrm{L}, \mathrm{T}=25^{\circ} \mathrm{C}$. 
S10. QCM-D data for lipid removal at $15^{\circ} \mathrm{C}$ by anionic surfactant SDBS and non-ionic surfactant $G_{1} C_{10}$ (frequency and dissipation change to $3^{\text {rd }}$ overtone).

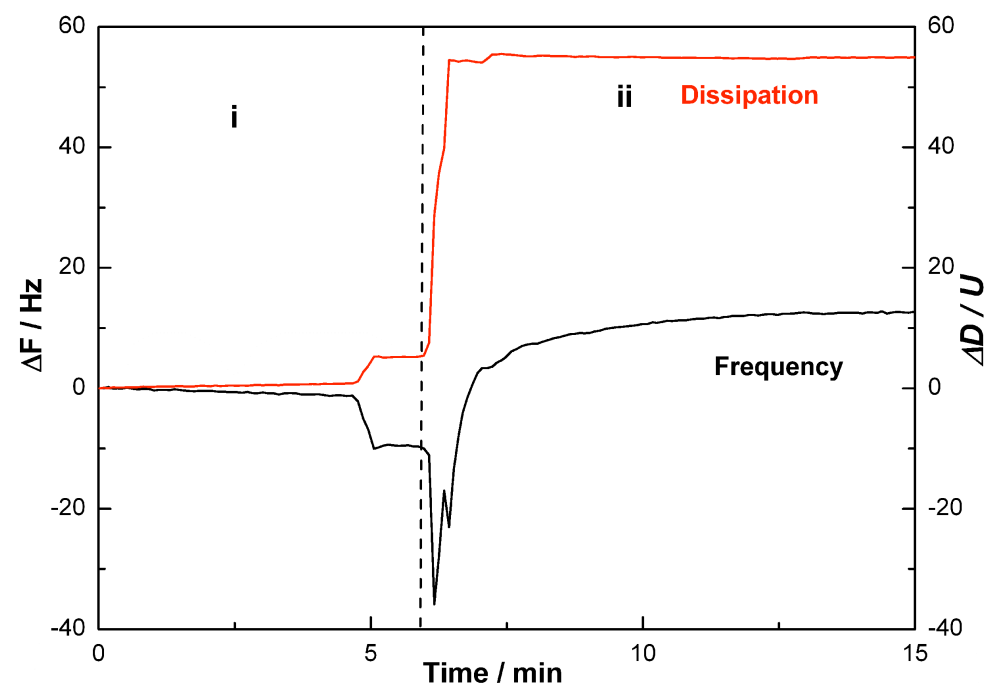

Figure S46. Frequency and dissipation changes on $3^{\text {rd }}$ overtone after exposure of the tristearin coated sensor to: i) 0-7 minutes, water; and ii) SDBS solution. [SDBS] $=40$ $\mathrm{mmol} / \mathrm{L}, \mathrm{T}=15^{\circ} \mathrm{C}$.

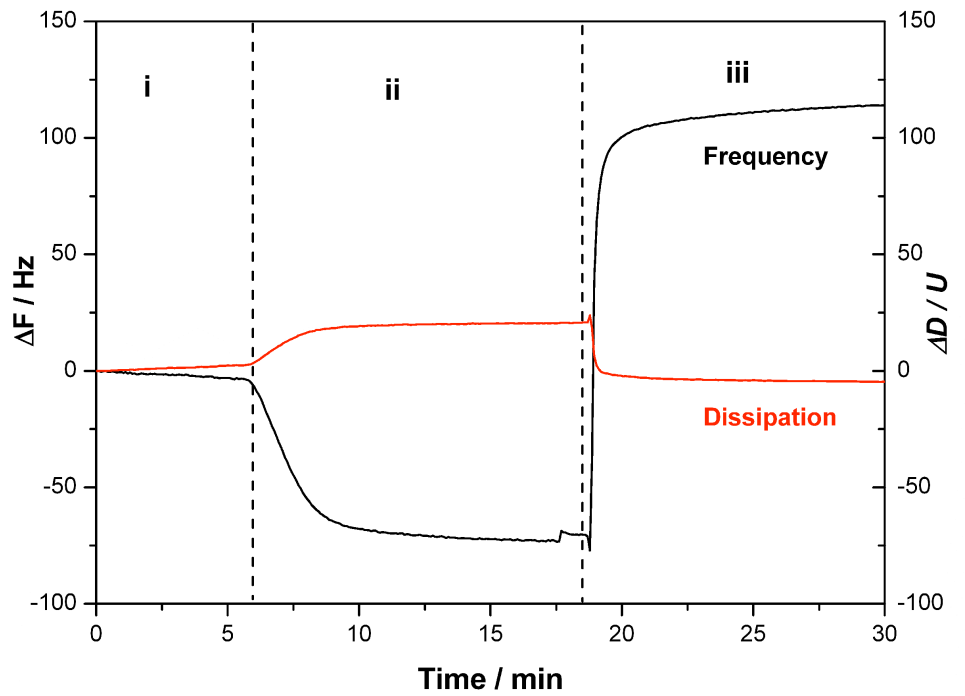

Figure S47. Frequency and dissipation changes to $3^{\text {rd }}$ overtone after exposure of the tristearin coated sensor to: i) 0-7 minutes, water; ii) 6-18 minutes, ND97 suspension was used to deposit nanoparticles; and iii) 18-30 minutes, $40 \mathrm{mmol} / \mathrm{L}$ SDBS solution was used for cleaning. $[\mathrm{ND} 97]=0.1 \mathrm{~g} / \mathrm{L},[\mathrm{SDBS}]=40 \mathrm{mmol} / \mathrm{L}, \mathrm{T}=15^{\circ} \mathrm{C}$. 


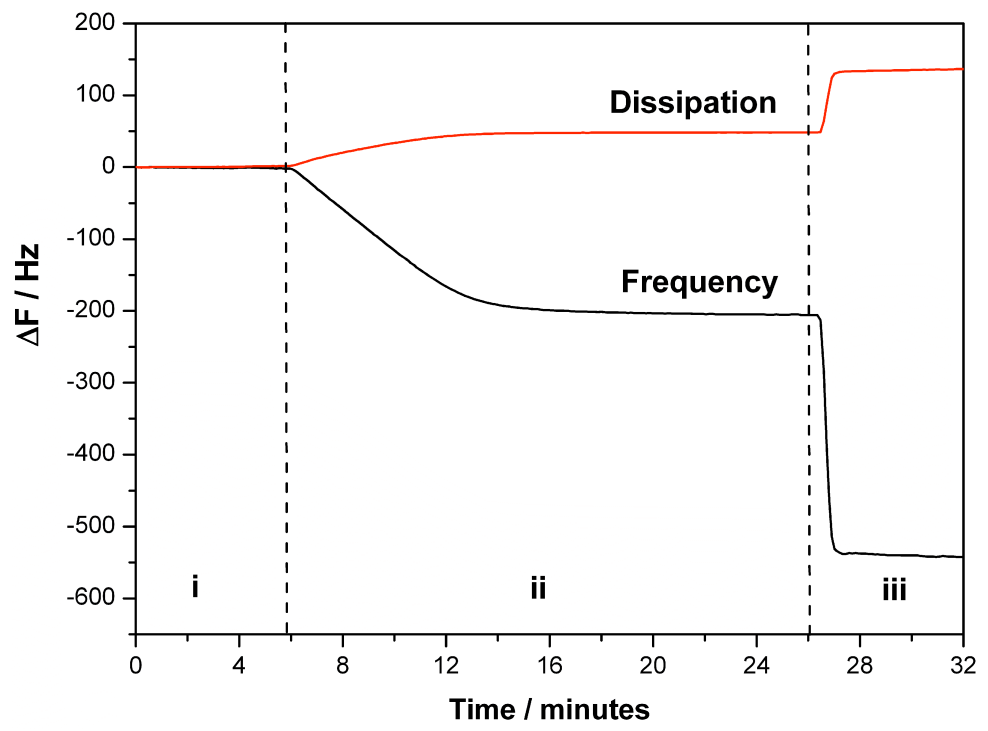

Figure S48. Frequency and dissipation changes to $3^{\text {rd }}$ overtone when the tristearin coated sensor was exposed to the following: i) 0-6 minutes, water is used to obtain a stable baseline; ii) 6-26 minutes, ND97 colloid was used; iii) 26-32 minutes $\mathrm{G}_{1} \mathrm{C}_{10}$ solution was used. $\left[\mathrm{G}_{1} \mathrm{C}_{10}\right]$ $=3.1 \mathrm{mmol} / \mathrm{L}$, [ND97] $=0.1 \mathrm{~g} / \mathrm{L}, \mathrm{T}=15^{\circ} \mathrm{C}$.

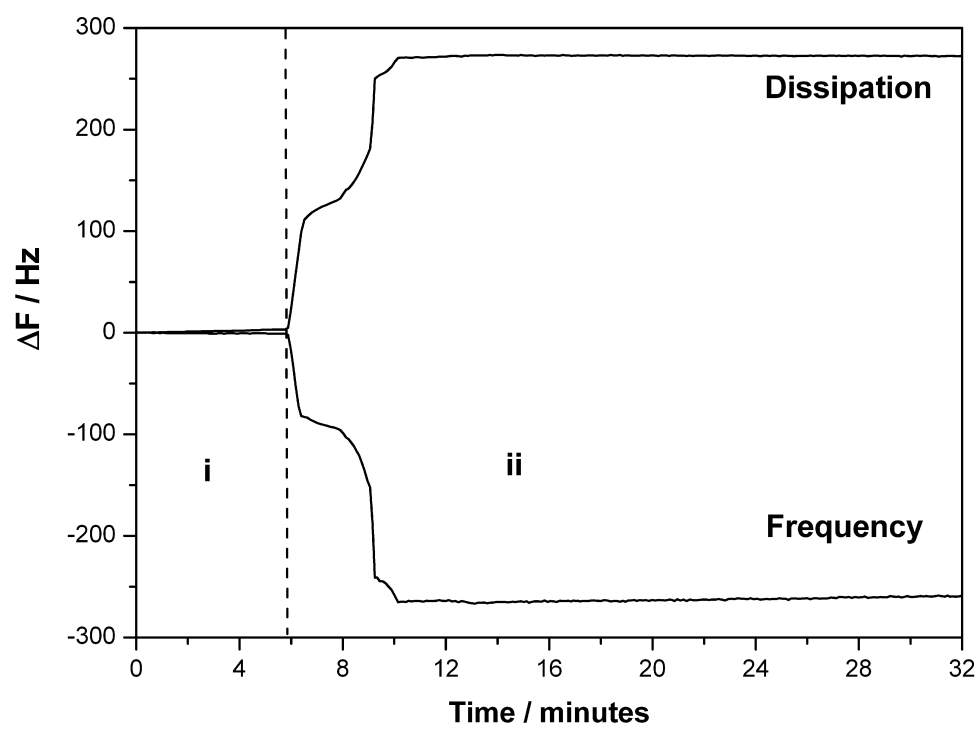

Figure S49. Frequency and dissipation changes to $3^{\text {rd }}$ overtone when the tristearin coated sensor was exposed to the following: i) 0-6 minutes, water is used to obtain a stable baseline; ii) 6-26 minutes, $\mathrm{G}_{1} \mathrm{C}_{10}$ solution were used, to remove tristearin lipid; iii) 26-32 minutes $\mathrm{G}_{1} \mathrm{C}_{10}$ solution was used for two sensors, to clean the QCM system. $\left[\mathrm{G}_{1} \mathrm{C}_{10}\right]=3.1 \mathrm{mmol} / \mathrm{L}, \mathrm{T}$ $=15{ }^{\circ} \mathrm{C}$. 


\section{Supporting Information References}

(1) Höök, F.; Rodahl, M.; Kasemo, B.; Brzezinski, P. Proc. Natl. Acad. Sci. U. S. A. 1998, 95, 12271.

(2) Voinova, M. V.; Rodahl, M.; Jonson, M.; Kasemo, B. Phys. Scr. 1999, 59, 391.

(3) Rodahl, M.; Hook, F.; Fredriksson, C.; A. Keller, C.; Krozer, A.; Brzezinski, P.; Voinova, M.; Kasemo, B. Faraday Discuss. 1997, 107, 229.

(4) Ohlsson, G.; Tigerstrom, A.; Hook, F.; Kasemo, B. Soft Matter 2011, 7, 10749.

(5) Christov, N. C.; Denkov, N. D.; Kralchevsky, P. A.; Broze, G.; Mehreteab, A. Langmuir 2002, 18, 7880 . 